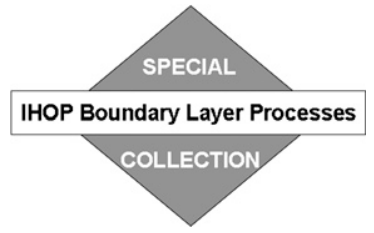

\title{
Simulating the IHOP_2002 Fair-Weather CBL with the WRF-ARW-Noah Modeling System. Part I: Surface Fluxes and CBL Structure and Evolution along the Eastern Track
}

\author{
Margaret A. LeMone, Fei Chen, Mukul Tewari, and Jimy Dudhia \\ National Center for Atmospheric Research,* Boulder, Colorado \\ BART GEERTS AND QUN MiAO \\ Department of Atmospheric Sciences, University of Wyoming, Laramie, Wyoming \\ RICHARD L. COULTER \\ Argonne National Laboratory, Chicago, Illinois \\ ROBERT L. GROSSMAN \\ Colorado Research Associates, Boulder, Colorado
}

(Manuscript received 13 March 2009, in final form 25 September 2009)

\begin{abstract}
Fair-weather data from the May-June 2002 International $\mathrm{H}_{2} \mathrm{O}$ Project (IHOP_2002) 46-km eastern flight track in southeast Kansas are compared to simulations using the advanced research version of the Weather Research and Forecasting model coupled to the Noah land surface model (LSM), to gain insight into how the surface influences convective boundary layer (CBL) fluxes and structure, and to evaluate the success of the modeling system in representing CBL structure and evolution. This offers a unique look at the capability of the model on scales the length of the flight track $(46 \mathrm{~km})$ and smaller under relatively uncomplicated meteorological conditions.

It is found that the modeled sensible heat flux $H$ is significantly larger than observed, while the latent heat flux (LE) is much closer to observations. The slope of the best-fit line $\Delta \mathrm{LE} / \Delta H$ to a plot of LE as a function of $H$, an indicator of horizontal variation in available energy $H+\mathrm{LE}$, for the data along the flight track, was shallower than observed. In a previous study of the IHOP_2002 western track, similar results were explained by too small a value of the parameter $C$ in the Zilitinkevich equation used in the Noah LSM to compute the roughness length for heat and moisture flux from the roughness length for momentum, which is supplied in an input table; evidence is presented that this is true for the eastern track as well. The horizontal variability in modeled fluxes follows the soil moisture pattern rather than vegetation type, as is observed; because the input land use map does not capture the observed variation in vegetation. The observed westward rise in CBL depth is successfully modeled for 3 of the 4 days, but the actual depths are too high, largely because modeled $H$ is too high. The model reproduces the timing of observed cumulus cloudiness for 3 of the 4 days.

Modeled clouds lead to departures from the typical clear-sky straight line relating surface $H$ to LE for a given model time, making them easy to detect. With spatial filtering, a straight slope line can be recovered. Similarly, larger filter lengths are needed to produce a stable slope for observed fluxes when there are clouds than for clear skies.
\end{abstract}

* The National Center for Atmospheric Research is sponsored by the National Science Foundation.

Corresponding author address: Margaret A. LeMone, NCAR Foothills Laboratory, 3450 Mitchell Lane, Boulder, CO 80301.

E-mail: lemone@ucar.edu

\section{Introduction}

This paper the first part of a two-part series that uses a combination of numerical simulations and observations of the fair-weather convective boundary layer (CBL) to explore the relationship of surface heterogeneity and associated fluxes $\left(\mathrm{W} \mathrm{m}^{-2}\right)$ of sensible heat 
$H$ and latent heat $\mathrm{LE}$, to $\mathrm{CBL}$ potential temperature $\Theta(\mathrm{K})$, mixing ratio $Q\left(\mathrm{~g} \mathrm{~kg}^{-1}\right)$, depth, and circulations on scales from 1 to $100 \mathrm{~km}$. At the same time, we evaluate the numerical simulations and the data. In this part, we focus on the impact of surface heterogeneity on horizontal variability in the CBL along a 46-km flight track (the "eastern track," in Fig. 1) in southeastern Kansas. In LeMone et al. (2010, hereafter Part II), we focus on $\sim 1-100-\mathrm{km}$ CBL structure in the region around the eastern track. The data were collected using aircraft, surface flux towers, and radar wind profilers, during May-June 2002, as part of the International $\mathrm{H}_{2} \mathrm{O}$ Project (IHOP_2002; Weckwerth et al. 2004). The eastern track is characterized by a mix of mostly grassland and winter wheat, with trees bordering many fields and waterways. The track extends across the eastern side of the Walnut River watershed southeast of Wichita and into the watershed to the east. The numerical simulations are done with the coupled Advanced Research Weather Research and Forecasting modeling system (ARWWRF; Skamarock et al. 2005), initialized using the HighResolution Land Data Assimilation System (HRLDAS; Chen et al. 2007), and coupled to the Noah land surface model (LSM; Ek et al. 2003).

The goal of IHOP_2002 is to improve prediction of continental warm-season precipitation in numerical weather prediction models by improving the measurement and use of water vapor data, and by improving representation of the evolution of water vapor in numerical weather prediction models. Land surface processes are emphasized because of their importance in the initiation and evolution of precipitating convection, both through the creation of upwelling regions favorable for storm formation and through destabilization through enhanced CBL growth (e.g., Anthes 1984; Segal et al. 1988; Pielke et al. 1991; Chen et al. 2001; Trier et al. 2004).

The relationship of the surface vegetation and soil moisture to the surface sensible and latent heat fluxes in the Southern Great Plains (SGP) has been studied extensively using data especially from the SGP Atmospheric Radiation Measurements (ARM) Cloud and Radiation Test bed (CART; Stokes and Schwartz 1994) and the four First International Satellite Land Surface Climatology Project (ISLSCP) Flux Experiment (FIFE; Sellers et al. 1992), and SGP-97 (more information is available online at http://hydrolab.arsusda.gov/sgp97/). In the mid-1990s, a group of scientists organized the Cooperative Atmosphere-Surface Exchange Study (CASES; LeMone et al. 2000, Yates et al. 2001) to focus on land surface interaction in the Walnut River basin in southeastern Kansas, which includes the eastern track. Examples of flux-surface relationship studies along the eastern track include Chen et al. (2003), LeMone et al.
(2003), Grossman et al. (2005), and LeMone et al. (2007b), while the match of observed fluxes to offline HRLDAS results was discussed in LeMone et al. (2007b, eastern track), and LeMone et al. (2008, western track).

The relationship of surface properties to CBL evolution for this region has been studied using other datasets or on larger scales. Santanello et al. (2007) used data from the ARM-CART site in central Oklahoma and a 1D surface-CBL model to show how surface properties at a point affect CBL growth at a point. Desai et al. (2006) and Reen et al. (2006) demonstrated the impact of soil moisture on the horizontal distribution of CBL depth in the SGP, using an idealized model, a mesoscale model, and aircraft and surface observations from SGP-97. Couvreux et al. (2009) used IHOP_2002 data, an idealized model, and MM5 simulations to look at the role of surface properties, advection, and CBL growth on the horizontal variability, looking at local and regional changes on scales up to hundreds of kilometers.

This work complements the earlier work by simultaneously focusing on scales larger than a point but smaller than $\sim 50 \mathrm{~km}$ (defined by the length of the eastern track) and focusing on fair weather, using detailed comparisons of model results to observations. The grid spacing needed for focusing on such small scales $(1 \mathrm{~km})$ is certainly smaller than optimum (e.g., Wyngaard et al. 1998; Wyngaard 2004). However, ARW-WRF is routinely run at high resolution (1-4-km grid spacing) for numerous applications, and some authors (e.g., Davis et al. 2008) report improvements in results down to $1-\mathrm{km}$ grid spacing; this work provides additional experience in examining the performance of ARW-WRF at these high resolutions. In addition, we extend the CASES work from a simple examination of surface influence on surface fluxes, to surface influence on the CBL. Restricting ourselves to fair-weather days allows a focus on surface layer fluxes and boundary layer structure without the complications of precipitating convection. In our comparisons, we address both uncertainties in the observations and model shortcomings. The data and results discussed herein and in Part II are being used to evaluate and improve the Noah LSM and the performance of the ARW-WRF model in representing fair-weather CBL structure and evolution. We look at 4 days, rather than one, to see what patterns emerge despite different synoptic situations and soil moisture and soil temperature distributions. To be sure, restricting ourselves to one geographic region has its disadvantages as well as advantages, but this is only part of a larger effort to determine the influence of surface processes on convective storm initiation and development. 

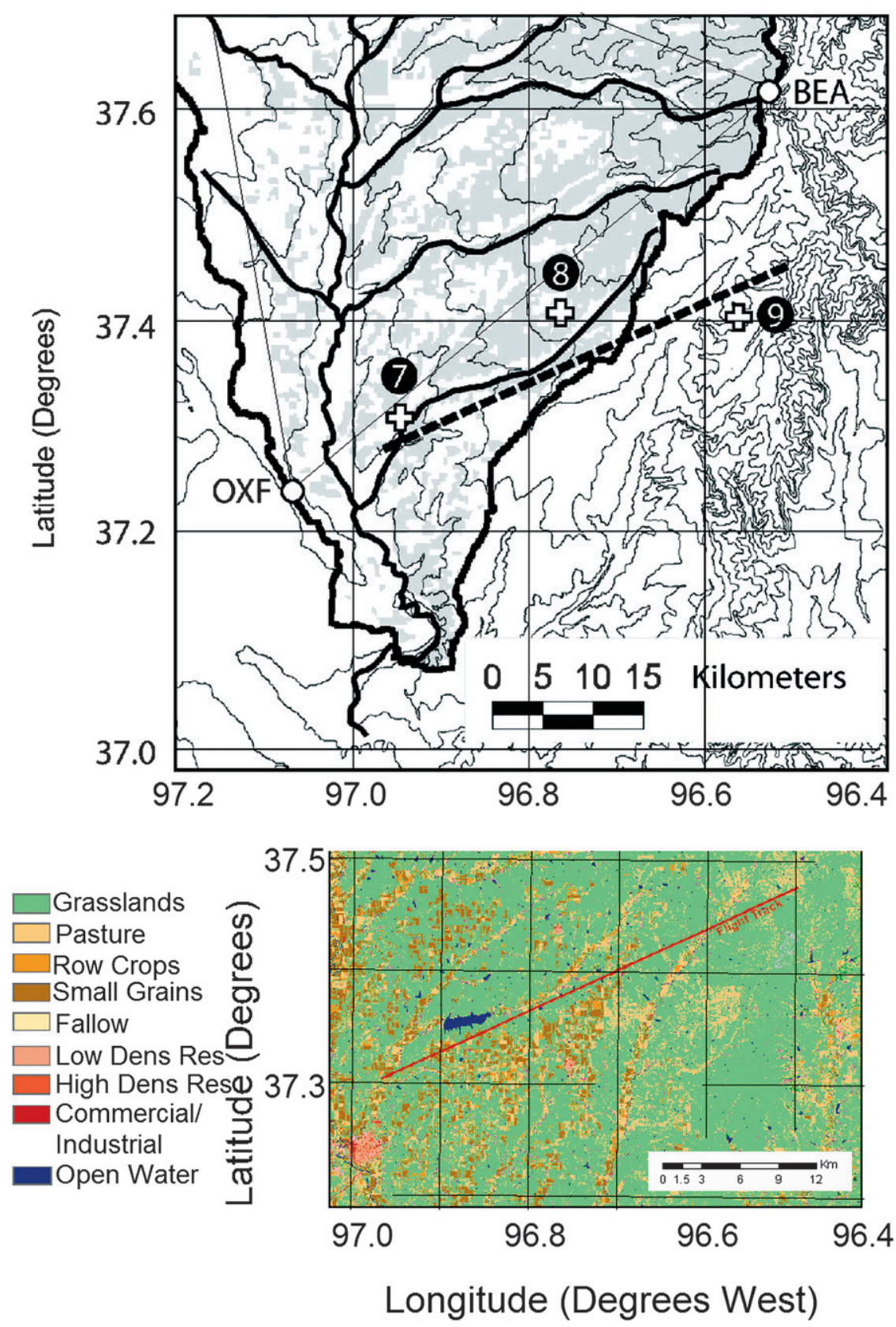

FIG. 1. Eastern track, instrumentation, and land use. (top) Instrumentation superimposed on terrain (contour interval $=20 \mathrm{~m}$ ) in the Walnut River watershed in southeast Kansas. Thick lines: outline of watershed, the Walnut River, and its tributaries. Within watershed: shading = grassland; no shading $=$ mostly cropland. Thick dashed line: eastern flight track. Partial triangle (fine solid line) connects the three ABLE radar wind profilers at Oxford (OXF; $37.27^{\circ} \mathrm{N}$, $\left.97.10^{\circ} \mathrm{W}\right)$; Beaumont $\left(\mathrm{BEA} ; 37.63^{\circ} \mathrm{N}, 96.54^{\circ} \mathrm{W}\right)$, and Whitewater [not shown, but on the NW vertex of the triangle at $37.84^{\circ} \mathrm{N}, 97.19^{\circ} \mathrm{W}$ or $63 \mathrm{~km} \mathrm{NNW}$ (azimuth $350^{\circ}$ ) of OXF]. (bottom) 30-m grid land use from National Land Cover Data (see online at http://landcover.usgs.gov), with flight track. In legend, "Dens" = "density" and "Res" = "residential." 
In this part, we assess the performance of HRLDAS (an offline version of the Noah LSM, hereafter referred to as "offline" or "offline Noah LSM" in comparisons) and the Noah LSM coupled to ARW-WRF, in simulating the variability in surface fluxes, as well as ARWWRF in simulating the spatial and temporal variability of the CBL along the eastern track. We look at the impacts of measurement uncertainty as well as model input and physics on the discrepancies. Data collection and analysis are discussed in section 2, with model runs and analysis of results summarized in section 3 . The results and conclusions are summarized in sections 4 and 5, respectively.

\section{Data collection and analysis}

Figure 1 shows the eastern track, surrounding instrumentation, and surface cover. Surface data, at the numbered sites, were collected from 10 May to 25 June 2002; the aircraft data (Table 1) are for four fair-weather days with scattered clouds or clear skies: 30 May, and 17, 20 , and 22 June. Radar wind profiler data (at the sites labeled BEA and OXF and a third site at the northwestern vertex of the outlined triangle) were being collected routinely as a part of the Argonne Boundary Layer Experiments (ABLE) facility (ABLE is no longer operating; however, the data are available online at http://gonzalo.er.anl.gov/ABLE; Klazura et al. 2006). Land use is shown in detail in the lower half of the figure; with grasslands shaded within the Walnut River watershed in the upper half. From the figure, the area surrounding the eastern part of the eastern track, as well as the region to the south, is primarily grassland, with crops (mainly winter wheat) becoming increasingly prevalent toward the west. The winter wheat was senescent along the flight track by 30 May, and it was harvested by 17 June. The dominant soil type in the region is silty clay loam (Soil Survey Geographic Database, more information is available online at http://dbwww.essc.psu.edu/ dbtop/doc/statsgo/statsgo_info.html; see Fig. 2), consistent with the observed near-surface soil type at the IHOP_2002 surface sites.

\section{a. Surface data}

Eddy-correlation fluxes and meteorological data were measured at three National Center for Atmospheric Research (NCAR) sites located at positions 7, 8, and 9 along the eastern track (Fig. 1), as described in LeMone et al. (2007a). All three sites were located on grassland. Because of frequent wetting and associated problems with the water vapor sensors at these sites, latent heat flux (LE) is estimated as a residual from the surface energy budget. Actual LE is available for 20 and

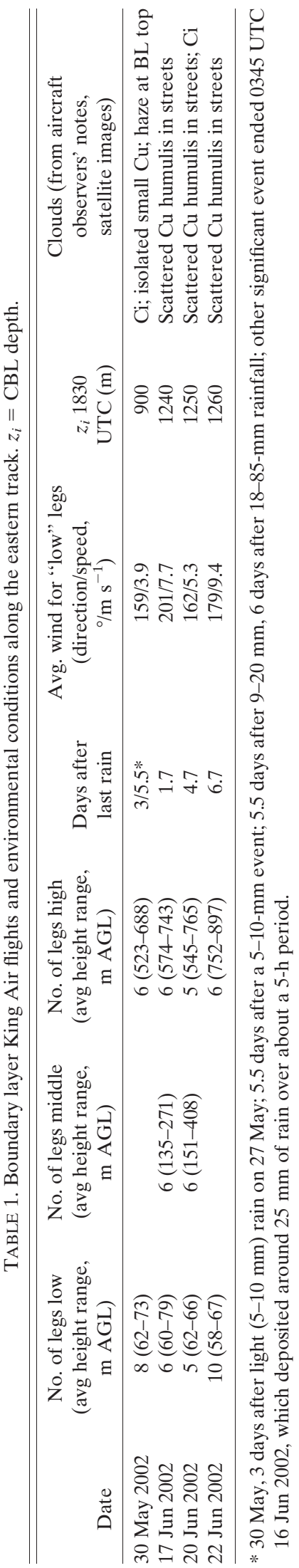




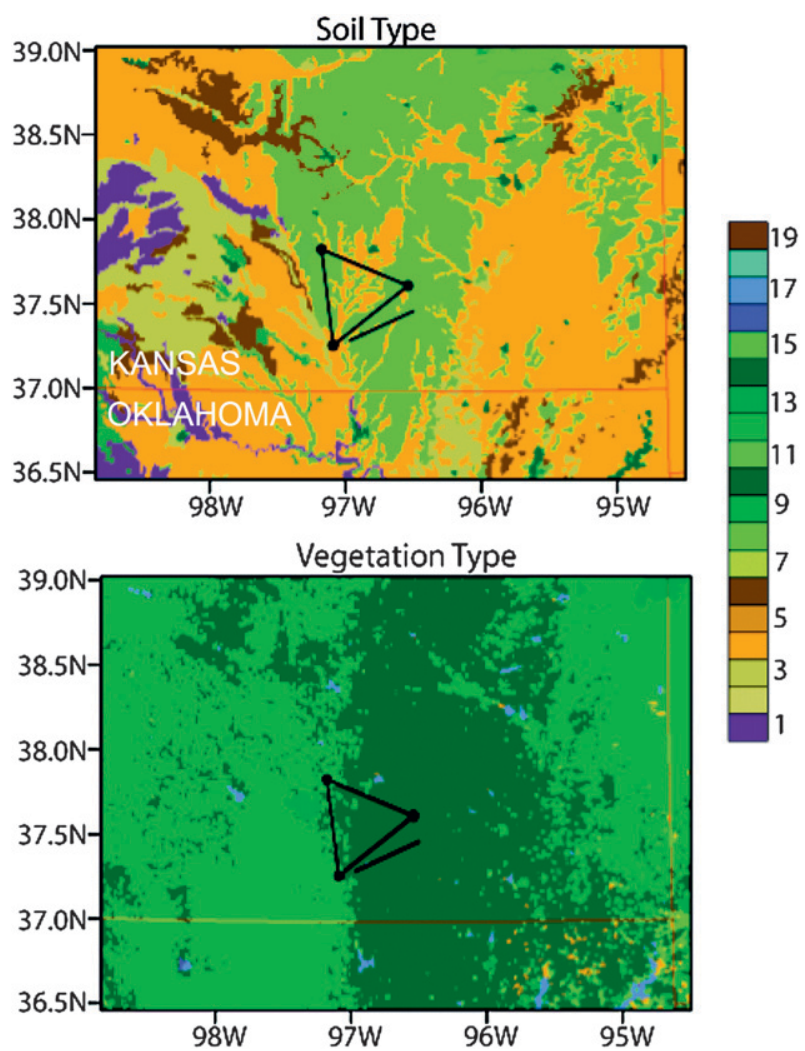

FIG. 2. (top) Soil type and (bottom) vegetation type for inner domain (d03). Soils near the eastern track (shown as solid line): $8=$ silty clay loam, $4=$ silt loam; elsewhere in figure: $1=$ sand, $2=$ loamy sand, $3=$ sandy loam, $6=$ loam, $7=$ sandy clay loam, $9=$ clay loam, $10=$ sandy clay, $11=$ silty clay, $12=$ clay, $13=$ organic material, and $14=$ water. For vegetation, near the eastern track: $10=$ grasslands, $12=$ croplands, $13=$ urban, $17=$ water; other vegetation in figure: 4 = deciduous broadleaf forests. The triangle in both (top) and (bottom) connects the locations of the three radar wind profilers.

22 June, but it could be slightly low. On days with bad (unrealistically low) LE, sonic temperature corrections for water vapor effects are also too low, leading to $H$ overestimates of up to $10 \%-15 \%$ (LeMone et al. 2007a). When the humidity instruments worked, these authors estimate that the surface energy budget balances to within $\sim 8 \%-20 \%$ of $R_{\text {net }}\left(\mathrm{W} \mathrm{m}^{-2}\right)$, the net radiation. No fluxes are available at site 7 on 30 May. For soil moisture, we use the Campbell Scientific CS-615 measurements taken continuously at $-0.05 \mathrm{~m}$ at each site, as well as manual measurements taken with a TRIME time-domain reflectometry (TDR) probe inserted into the soil at a $45^{\circ}$ angle.

\section{b. Aircraft data}

Aircraft data (Table 1) were collected using the University of Wyoming King Air gust-probe aircraft during four IHOP_2002 boundary layer heterogeneity
TABLE 2. Average fractional standard error $\left(S_{E}\right)$ for overlapping 4-km-averaged fluxes, based on averages of the standard errors at each point along the grand-average leg.

\begin{tabular}{lcccc}
\hline \hline Date & $\begin{array}{c}\text { No. of } \\
\text { legs }\end{array}$ & $S_{E}(H) / H$ & $\begin{array}{c}S_{E}(\mathrm{LE}) / \mathrm{LE} \\
\text { LiCor }\end{array}$ & $\begin{array}{c}S_{E}(\mathrm{LE}) / \mathrm{LE} \\
\text { Lyman }\end{array}$ \\
\hline 30 May & 8 & 0.109 & 0.123 & 0.120 \\
17 Jun & 6 & 0.107 & 0.113 & 0.109 \\
20 Jun & 5 & 0.275 & 0.272 & 0.270 \\
22 Jun & 10 & 0.066 & 0.080 & 0.077 \\
\hline
\end{tabular}

(BLH) missions. Each mission consisted of repeated straight and level flight legs along the eastern track, with occasional soundings to check mixed-layer (nearconstant $\Theta$ ) depth. At least five legs were flown at 60-70 $\mathrm{m}$ above ground level (AGL), with at least one higher-altitude interval represented. We attempted to keep the higher legs at a constant fraction of the CBL depth. All four days experienced fair weather, with few clouds and wind from approximately south-southwest to southeast at speeds from 3.9 to $9.4 \mathrm{~m} \mathrm{~s}^{-1}$ at $\sim 65 \mathrm{~m}$ AGL. The last rainfall was at least two days previous. The eastern track has the greenest and densest vegetation [highest normalized differential vegetation index (NDVI), see Fig. 4 in LeMone et al. 2007a], and the coolest radiometric surface temperature $T_{s}(\mathrm{~K})$ of the three BLH tracks flown during IHOP_2002 (LeMone et al. 2007b compare the eastern and western track in their Table 1 and notes that the central track has intermediate characteristics).

The King Air instrumentation is described in detail in LeMone et al. (2007a,b). Aircraft-relative winds were measured by a Rosemount $858 \mathrm{AJ} / 1332$ differential pressure gust-probe system. Aircraft position and motion relative to the ground were measured by a Honeywell Laseref SM inertial navigation system and corrected using GPS to within $100 \mathrm{~m}$ horizontally. Aircraft altitude was based on a King KRA5 radio altimeter for heights below $610 \mathrm{~m}$; and an APN159 radar altimeter for heights above $610 \mathrm{~m}$. Water vapor densities from the LiCor 6262 gas analyzer and a Lyman- $\alpha$ instrument from NCAR were used to estimate $Q$. Both instruments were used in estimates of fluxes; but the Lyman $\alpha$ was used for means, since it is referenced to an EG\&G chilled-mirror dewpointer. A downward-looking Heiman KT-19.85 radiometer measured $T_{s}$; while the potential temperature $\theta$ was calculated from the pressure from a Rosemount 1201 sensor and air temperature measured from a fastresponse reverse-flow platinum resistance thermometer built at the University of Wyoming. Data were recorded at $25 \mathrm{~Hz}$.

Fluxes from the aircraft are based on fluctuations relative to flight leg linear trends, following LeMone 


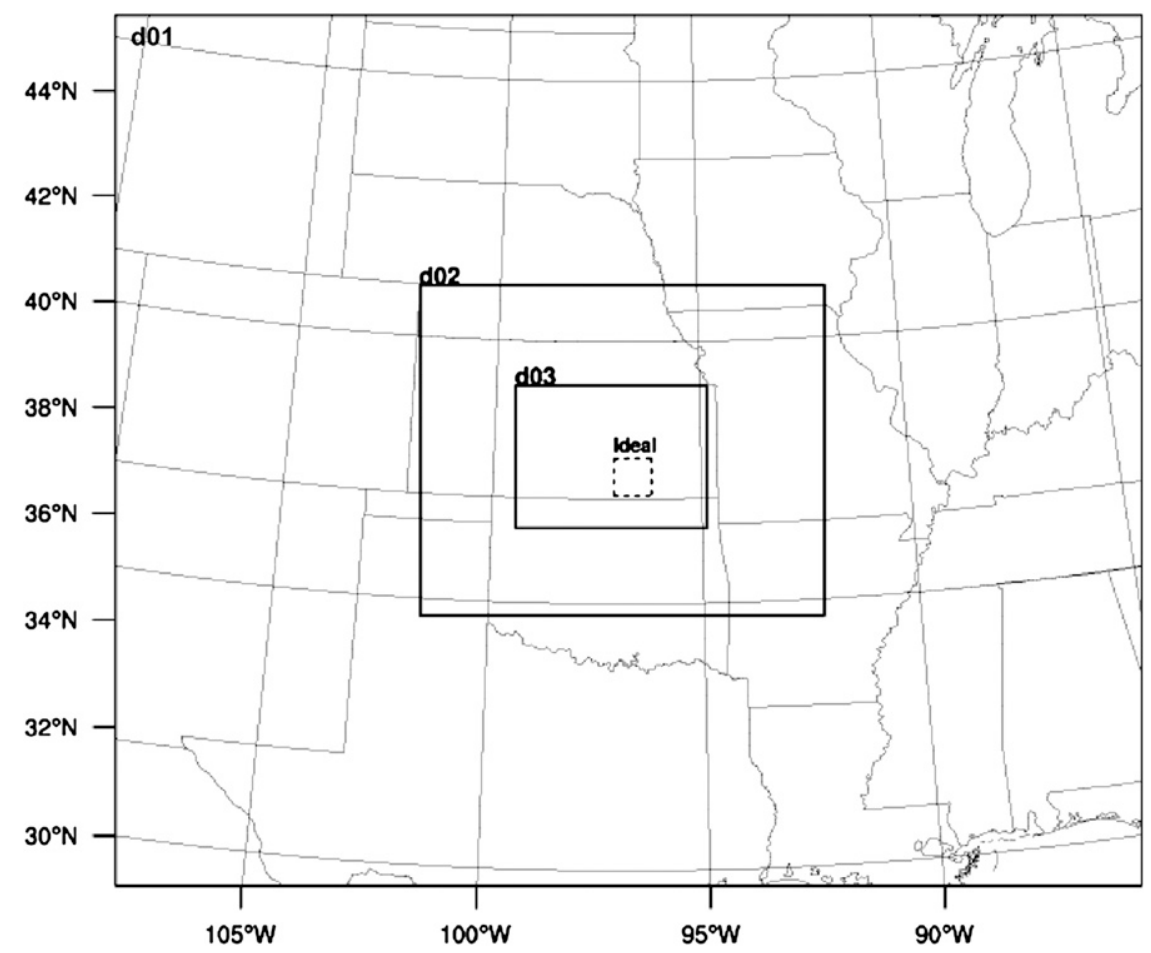

FIG. 3. Domains for ARW-WRF runs. Horizontal distance between grid points: for outer (d01): $9 \mathrm{~km}$; intermediate domain (d02): $3 \mathrm{~km}$; inner domain (d03): $1 \mathrm{~km}$. The dashed "ideal" square represents the single or outer domain for the idealized runs using 20 Jun data, which varies in size according to grid spacing.

et al. (2008), with 4-km averages at 1-km intervals for comparison to surface and model fluxes, and $1-\mathrm{km}$ averages for looking at the impact of filtering on the slope $\Delta \mathrm{LE} / \Delta H$ from an $H$ versus LE plot for estimates along the grand-average flight track (to be discussed below). Including fluctuations out to flight leg scale leads to increased uncertainty due to inclusion of the largerscale fluxes, but provides values that should match both LSM-based fluxes and surface observations if both aircraft and surface sensors sample the dominant land-use types (grassland and winter wheat; Fig. 1).

The average fractional standard error for the $4-\mathrm{km}$ averaged aircraft fluxes in Table 2 is of the order of $10 \%$ for 3 of the 4 days, with higher values associated with fewer legs. The relative size of the numbers and magnitudes is similar to the estimates of the fractional random error $\sigma^{*}(F)$ in Alfieri et al. (2009), which are based on Mann and Lenschow (1994). In spite of the various sources of bias and uncertainty, aircraft $H$ extrapolated to the surface from aircraft-derived profiles was only $\sim 10 \%$ lower than surface measurements; while aircraftbased LE extrapolated to the surface is $5 \%$ (the three June days) to $15 \%$ (30 May) higher than surface measurements.

\section{c. Radar wind profiler data}

The radar $(915 \mathrm{MHz})$ wind profilers at Beaumont and Oxford, Kansas (Fig. 1), were used to obtain CBL depth. These radars sense inhomogeneities in the clear-air refractive index, which are due mainly to variations in the water vapor density. The vertical resolution of the profiler data is on the order of $60 \mathrm{~m}$. CBL depth was defined as the center height of the gate just below the maximum signal-to-noise (SNR) ratio drop-off rate with height (Coulter and Holdridge 1998).

\section{d. Wyoming Cloud Radar data}

The Wyoming Cloud Radar (WCR) was used to estimate CBL depth along the flight track. The WCR is a 3-mm (95 GHz) multiantenna Doppler radar (Pazmany et al. 1994). During IHOP_2002, the radar's two antennas looked vertically up and down from the aircraft. The vertical resolution was $\sim 30 \mathrm{~m}$, and the nearest reliable gates were centered $120 \mathrm{~m}$ below and $105 \mathrm{~m}$ above the aircraft, resulting in a $225-\mathrm{m}$ "blind" zone approximately centered on the aircraft. Echo strength is measured in terms of equivalent reflectivity, which is derived 
TABLE 3. Sensitivity of inner-domain-averaged CBL depth $h_{\mathrm{WRF}}$ to horizontal grid spacing, surface perturbations, filtering, and domain depth, for idealized runs based on $20 \mathrm{Jun}$ input data at $37.4188^{\circ} \mathrm{N}, 96.6472^{\circ} \mathrm{W}$. Runs use ARW-WRF V3, with uniform vegetation (grassland) and soil texture (silty clay loam); initial $T_{s}$ and/or volumetric soil moisture varied using random perturbations. "Filt" refers to the Knievel et al. (2007) filter used in ARW-WRF to damp out unresolved motions; "Nest" refers to whether the finest resolution was a result of nesting. $\mathrm{Y}=$ "yes," $\mathrm{N}=$ "no."

\begin{tabular}{|c|c|c|c|c|c|c|c|c|}
\hline Run & $\begin{array}{l}\text { Surface grid } \\
\text { spacing }(\mathrm{km})\end{array}$ & $\begin{array}{l}\text { Atmospheric grid } \\
\text { spacing }(\mathrm{km})\end{array}$ & $\begin{array}{l}\text { Domain } \\
\text { top }(\mathrm{km})\end{array}$ & Filt & Nest & $\begin{array}{l}h_{\mathrm{WRF}} 1800 \\
\mathrm{UTC}(\mathrm{km})\end{array}$ & $\begin{array}{l}h_{\mathrm{WRF}} 2100 \\
\mathrm{UTC}(\mathrm{km})\end{array}$ & Remarks \\
\hline \multicolumn{9}{|c|}{ Initial surface temperature perturbations } \\
\hline T1NF & 1 & 1 & 20 & $\mathrm{~N}$ & $\mathrm{~N}$ & 1.14 & 1.68 & $\begin{array}{c}\text { Weak cellular } 1800 \text { UTC, } \\
\text { Weak rolls } 2100 \text { UTC }\end{array}$ \\
\hline $\mathrm{T} 1$ & 1 & 1 & 20 & $\mathrm{Y}$ & $\mathrm{N}$ & 1.14 & 1.68 & No CBL convective structures \\
\hline $\mathrm{T} 2$ & 2 & 2 & 20 & $\mathrm{Y}$ & $\mathrm{N}$ & 1.14 & 1.68 & No CBL convective structures \\
\hline $\mathrm{T} 4$ & 4 & 4 & 20 & $\mathrm{Y}$ & $\mathrm{N}$ & 1.14 & 1.68 & No CBL convective structures \\
\hline $\mathrm{T} 10$ & 10 & 10 & 20 & $\mathrm{Y}$ & $\mathrm{N}$ & 1.14 & 1.68 & No CBL convective structures \\
\hline \multicolumn{9}{|c|}{ Initial surface temperature and soil moisture perturbations } \\
\hline TS5 & 5 & 5 & 20 & $\mathrm{Y}$ & $\mathrm{N}$ & 1.17 & 1.67 & $\begin{array}{l}\text { Irregular, } 50-\mathrm{km} \text { roll-like } \\
\text { structure at CBL top, } \\
\text { 1800-2100 UTC }\end{array}$ \\
\hline TS1 & 1 & 1 & 20 & $\mathrm{Y}$ & $\mathrm{N}$ & 1.16 & 1.68 & Rolls \\
\hline TS1NF & 1 & 1 & 20 & $\mathrm{~N}$ & $\mathrm{~N}$ & 1.16 & 1.66 & Rolls \\
\hline TS0.5 & 0.5 & 0.5 & 20 & $\mathrm{Y}$ & $\mathrm{N}$ & 1.20 & 1.69 & Rolls \\
\hline TS0.5s & 0.5 & 0.5 & 5 & $\mathrm{Y}$ & $\mathrm{N}$ & 1.26 & 1.67 & Rolls \\
\hline TS0.5NFs & 0.5 & 0.5 & 5 & $\mathrm{~N}$ & $\mathrm{~N}$ & 1.17 & 1.67 & $\begin{array}{l}\text { Cellular convection by } \\
2100 \text { UTC }\end{array}$ \\
\hline TSmix1_0.5s & 1 & 0.5 & 5 & $\mathrm{Y}$ & $\mathrm{N}$ & 1.17 & 1.67 & Rolls \\
\hline TSmix1_0.33NFs & 1 & 0.333 & 5 & $\mathrm{~N}$ & $\mathrm{Y}$ & 1.17 & 1.67 & Rolls, cells to north \\
\hline Tsmix1_0.2s & 1 & 0.2 & 5 & $\mathrm{~N}$ & $\mathrm{Y}$ & 1.17 & 1.67 & $\begin{array}{l}\text { Rolls } 1600 \text { UTC but mostly } \\
\text { cellular after }\end{array}$ \\
\hline TSmix2_0.5sNF & 2 & 0.5 & 5 & $\mathrm{~N}$ & $\mathrm{Y}$ & 1.17 & 1.67 & Rolls \\
\hline
\end{tabular}

from power under the assumption that the scatterers (insects in this case) are spherical water droplets.

The WCR CBL depth $z_{i_{-} \text {wCR }}$ was determined from the reflectivity above plumes (Miao et al. 2006) after vertical ( 3 gates or $45 \mathrm{~m}$ ) and horizontal $(10 \mathrm{~s}$ or $\sim 830 \mathrm{~m}$ ) smoothing. Usually, $z_{i}$ wCR was found from the upward-looking beam, and defined as where the rangecorrected reflectivity reaches a minimum-between the drop-off at plume top and the increase in reflectivity due to range-corrected noise. For the downward-looking beam, $z_{i \text { WCR }}$ was taken as the height of an arbitrary reflectivity value ranging between -28 and $-26 \mathrm{dBZ}$. This level is characterized by a large reflectivity gradient. Since the scatterers are small insects trying to fly downward, reflectivity becomes small between plumes and CBL depth is often not detectable there (Geerts and Miao 2005).

To determine spatial trends in $z_{i_{-} \mathrm{WCR}}$, values were plotted as a function of longitude for each flight leg and fitted to a least squares straight line. The best-fit line for each leg was used to determine $z_{i \_ \text {WCR }}$ at the leg end points and these were assigned the leg center times. Least squares best-fit lines were then determined for the resulting two $z_{i_{-} \text {WCR }}$ time series. The equations for these two lines were then used to obtain the leg-end CBL depths at 1830 UTC, which is close to the center time for the flight mission.

\section{ARW-WRF runs}

\section{a. The control simulation}

The ARW-WRF model is nonhydrostatic and compressible, with a mass coordinate system (Skamarock et al. 2005). We integrated ARW-WRF version 2.1.2 over the three nested domains shown in Fig. 3. The grid spacings (number of points) for these three domains are $9 \mathrm{~km}(237 \times 201), 3 \mathrm{~km}(280 \times 229)$, and $1 \mathrm{~km}(391 \times$ $289)$, respectively. The vertical grid contains 30 full sigma levels from the surface to $50 \mathrm{hPa}$, of which the lowest 8 levels are below $1 \mathrm{~km}$ AGL in order to have finer resolution in the $\mathrm{CBL}$, with the lowest level at $28 \mathrm{~m}$ AGL. A 24-h simulation starting at 1200 UTC was conducted for the 4 days the aircraft flew (Table 1), with the initial and boundary conditions from the National Centers for Environmental Prediction (NCEP) 6-hourly Eta Data Assimilation System (EDAS) on a 40-km grid.

The physical parameterizations used include a bulk microphysics scheme based on Lin et al. (1983), the Dudhia (1989) shortwave radiation scheme, the Rapid Radiative Transfer Model (RRTM) longwave parameterization scheme (Mlawer et al. 1997), the Yonsei University (YSU) PBL scheme (Hong et al. 2006), and the Noah LSM (Chen and Dudhia 2001; Ek et al. 2003). The Noah LSM has a single vegetation canopy layer and 

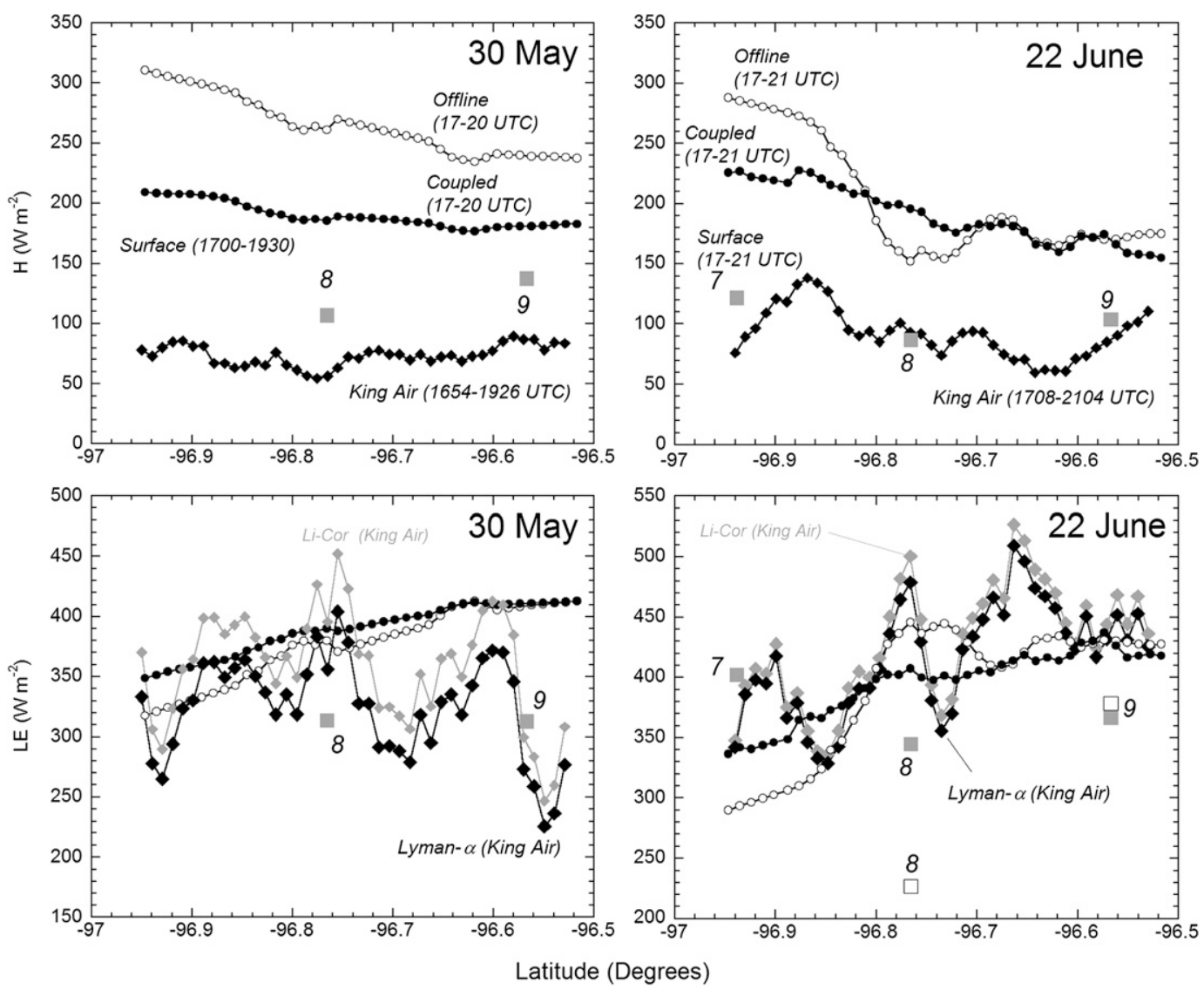

FIG. 4. For 30 May and 22 Jun 2002, sensible and latent heat fluxes $H$ and LE for King Air grand-average leg (overlapping 4-km averages at 1-km intervals, diamonds), surface flux towers (closed squares), and Noah LSM (overlapping 4.4-km averages at 1.1-km intervals): coupled $=$ solid circles; offline $=$ open circles, for corresponding times. Distance corresponding to $0.1^{\circ}$ longitude: $8.83 \mathrm{~km}$ in east-west direction; $9.74 \mathrm{~km}$ along eastern track. For 30 May, surface fluxes are for sites 8 and 9 only; site 7 malfunctioned. For 22 Jun, measured surface LE (open squares) is included as well as LE found as residual from surface energy budget (closed squares) for sites 8 and 9.

predicts volumetric soil moisture and temperature in four soil layers. The depths of the individual soil layers are sequentially $0.1,0.3,0.6$, and $1.0 \mathrm{~m}$. The root zone is contained in the upper $1 \mathrm{~m}$ (top 3 layers) and its depth depends on vegetation type.

In the control simulation, the Noah LSM was initialized using volumetric soil moisture and temperature profiles and skin temperatures obtained from HRLDAS (Chen et al. 2007), which is a version of the Noah LSM run offline but on the same nested grid for an 18-month spinup period ending at the initialization time of each simulation (here, runs start on 1 January 2001). This land surface initialization uses a variety of observed and analyzed conditions including 1) National Weather Service (NWS) Office of Hydrology stage 4 rainfall data on a 4-km national grid (Fulton et al. 1998); 2) $0.5^{\circ}$ hourly downward solar radiation derived from the Geostationary Operational Environmental Satellite-8 and -9 (GOES-8 and GOES-9) as described by Pinker et al. (2002);3) near- surface atmospheric temperature, humidity, wind, downward longwave radiation, and surface pressure from 3-hourly NCEP EDAS analyses; 4) a land-use characteristics table based on the Moderate Resolution Imaging Spectroradiometer (MODIS; Fig. 2) from the Boston University Department of Geography (more information is available online at http://www-modis.bu.edu/ landcover/), rather than the default 1-km horizontal resolution U.S. Geological Survey 24-category land-use table; 5) 1-km horizontal resolution Soil Survey Geographic (SSURGO, formerly STATSGO) database soil texture maps (Fig. 2); and 6) $0.15^{\circ}$ monthly satellitederived green vegetation fraction based on 5-yr averages (Gutman and Ignatov 1997).

The choice of $1 \mathrm{~km}$ for the inner grid reflects the desire to capture as much as possible the observed horizontal variability in surface properties as well as to resolve the mesoscale eddies (10 $\mathrm{km}$ and greater) that are the subject of Part II; the choice of the YSU scheme 
TABLE 4. Comparison of observed to modeled surface fluxes. Surface (subscript 0 ) values are found by assuming the fractional change between the flight level and the surface is the same as for the aircraft profiles of $H$ and LE LiCor (for both LiCor and Lyman $\alpha$ ) interpolated to $1830 \mathrm{UTC}$. $\mathrm{Li}=\mathrm{LiCor} ; \mathrm{Ly}=\operatorname{Lyman} \alpha$.

\begin{tabular}{|c|c|c|c|c|c|c|}
\hline Date & $H$ & $H_{0}$ & LE Li/Ly & $\mathrm{LE}_{0} \mathrm{Li} / \mathrm{Ly}$ & $H_{0}+\mathrm{LE}_{0} \mathrm{Li} / \mathrm{Ly}$ & $\Delta \mathrm{LE} / \Delta H^{*} \mathrm{Li} / \mathrm{Ly}$ \\
\hline \multicolumn{7}{|l|}{30 May } \\
\hline Obs & 73 & 82 & $358 / 324$ & $341 / 309$ & $423 / 391$ & $-2.6 / 2.3$ \\
\hline Noah LSM offline & & 266 & & 374 & 641 & -1.3 \\
\hline Noah LSM coupled & & 190 & & 388 & 578 & -2.0 \\
\hline \multicolumn{7}{|l|}{17 June } \\
\hline Obs & 93 & 99 & $387 / 365$ & $366 / 345$ & $465 / 444$ & - \\
\hline Noah LSM offline & & 176 & & 445 & 621 & -1.3 \\
\hline Noah LSM coupled & & 179 & & 439 & 619 & -1.5 \\
\hline \multicolumn{7}{|l|}{20 June } \\
\hline Obs & 69 & 75 & $426 / 404$ & $370 / 352$ & $445 / 427$ & - \\
\hline Noah LSM offline & & 188 & & 389 & 576 & -1.2 \\
\hline Noah LSM coupled & & 185 & & 402 & 587 & -1.2 \\
\hline \multicolumn{7}{|l|}{22 June } \\
\hline Obs & 92 & 99 & $428 / 406$ & $382 / 372$ & $481 / 470$ & $-2.08 /-2.00$ \\
\hline Noah LSM offline & & 199 & & 395 & 594 & -1.2 \\
\hline Noah LSM coupled & & 191 & & 395 & 586 & -1.1 \\
\hline
\end{tabular}

* Slopes for Noah LSM: used running 10-point average for coupled days with clouds (20 and 22 June) to filter out clouds; slopes for clear days or offline do not depend on filter. For observations: slopes apply to data filtered with $10-\mathrm{km}$ running mean. Because of scatter in slope-vs-filter-length plots, slope is average for 9-11-km values for 22 June; slope data interpolated to $10 \mathrm{~km}$ for $30 \mathrm{May}$ after drawing a smooth line through the data.

was arbitrary. It is recognized that PBL schemes like the YSU scheme were designed for larger grid spacing. However, in ARW-WRF hurricane simulations using the YSU PBL scheme, Davis et al. (2008) found ARWWRF to perform better with a $1.33-\mathrm{km}$ grid than a $4-\mathrm{km}$ grid. Similarly, Y. Chen et al. (2008, personal communication) continued to have good results with YSU in ARW-WRF when they extended their simulations of an idealized hurricane down to 555-m horizontal grid spacing (W. Wang 2009, personal communication).

\section{b. Sensitivity tests}

Several additional runs (Table 3 ) were conducted using the public release version of ARW-WRF version 3 (V3) with the same physics schemes to assess effects of atmosphere- and surface-grid spacing, lower boundary conditions, domain depth, and filtering on CBL growth and convective structure. The domain (Fig. 3), centered at $37.4188^{\circ} \mathrm{N}, 96.6472^{\circ} \mathrm{W}$, varied with size according to the grid spacing. Initial conditions on the ARW-WRF grid were set equal to the values at the central point. Initial volumetric soil moisture and/or $T_{s}$ were then perturbed randomly using a uniform distribution with a range of \pm 0.02 for volumetric soil moisture and $\pm 0.01 \mathrm{~K}$ for $T_{s}$ relative to the mean. Because input data were based on only one point, winds had to be determined using an option in ARW-WRF that maintains the geostrophic part with an implicit pressure gradient, with only the ageostrophic component responding to the
Coriolis acceleration. In the table, the runs are defined according to surface grid spacing, atmosphere grid spacing, ${ }^{1}$ domain top, presence of the default Knievel et al. (2007) filter in this version of ARW-WRF (the control runs did not use the Knievel filter), and what surface variables were perturbed. In some of the higherresolution idealized runs, an inner grid is used (not shown in Fig. 3).

\section{c. Processing of model output}

The control run output analyzed was hourly and for the 1-km grid. To optimize comparison with fluxes along the eastern track, LSM values were time averaged and filtered to correspond to about the same horizontal scale and time interval as the filtered aircraft fluxes. Because of the east-northeast-west-southwest orientation of the eastern track, the 1-km Cartesian grid points did not correspond exactly to the $1-\mathrm{km}$ points along the track. This resulted in more than one model point being assigned to a given observation point at some longitudes. These duplicate points were averaged, and then a 4-point filter was applied. Since a $1-\mathrm{km}$ east-west

\footnotetext{
${ }^{1}$ For different atmosphere and surface grids, one grid square corresponds exactly to an integral number of the other. For example, four 500-m surface grid squares correspond to one $1-\mathrm{km}$ atmosphere grid square. In this case, the atmosphere grid responds to the average of the four surface grids, and the four surface grid squares all respond to the value for the atmosphere grid square.
} 

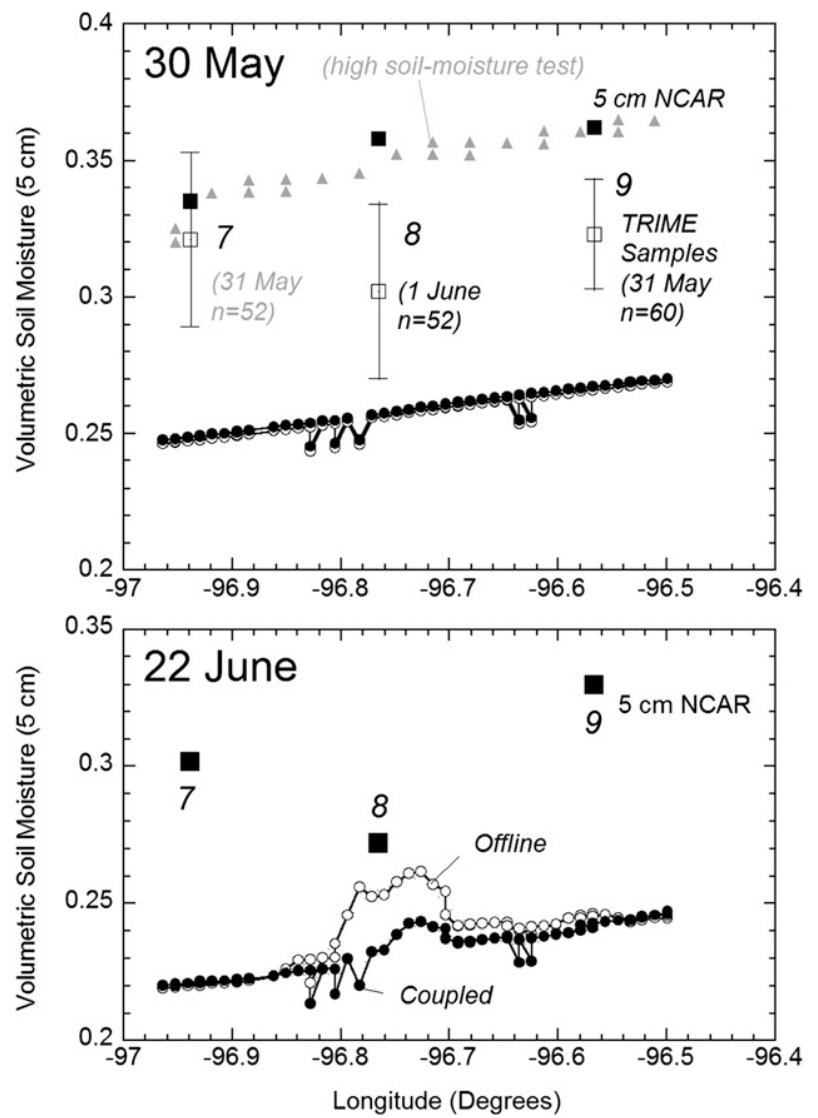

FIG. 5. Volumetric soil moisture for times in Fig. 4, from coupled and offline Noah LSM runs and surface data. Noah LSM level 1 soil moisture $(0-10 \mathrm{~cm})$ : open circles $=$ offline; solid circles $=$ coupled. Extra points result from fit of flight-track points to model grid. Observations: solid squares $=$ NCAR soil moisture; outlined squares = TRIME soil moisture; vertical lines show standard deviations. Gray triangles = volumetric soil moisture values for offline sensitivity test. Manual measurements were taken within about $30 \mathrm{~m}$ from the flux tower; see LeMone et al. (2007a) for further details.

distance in the model corresponded to $1.1 \mathrm{~km}$ along the flight track, this led to a roughly 4.4-km smoothing. The duplicate points had little effect on the leg means, so they were computed directly from the model grid points along the flight track.

The YSU PBL top in ARW-WRF ( $\left.h_{\mathrm{WRF}}\right)$, available as standard output, is defined as the height $z$ at which the virtual potential temperature difference $\left(\Theta_{v}+1 \mathrm{~K}\right)_{\text {level } 1}-$ $\Theta_{v}(z)=0$. It follows that $h_{\mathrm{WRF}}$ lies between the grid points in the vertical. At the expected range of CBL depths around noon (1-2 km AGL), the vertical grid spacing is between 200 and $300 \mathrm{~m}$. Values were extracted along the flight track for direct comparison with observed data. For the sensitivity runs, the CBL top was averaged over the innermost domain to avoid localized changes associated with large eddies.

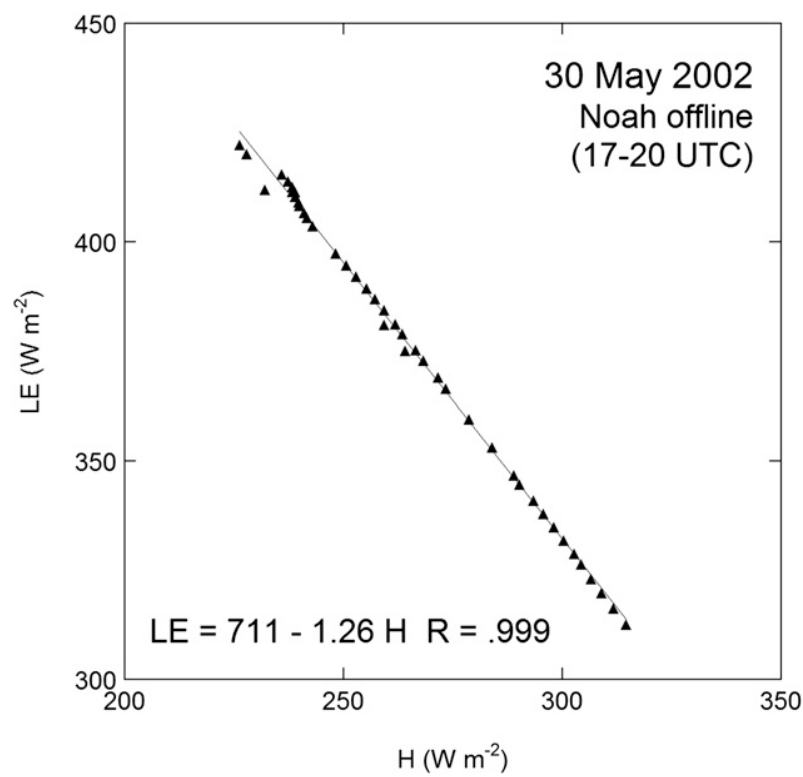

FIG. 6. LE as a function of $H$, for points along eastern track, from control offline Noah LSM run, averaged between 1700 and 2000 UTC 30 May 2002.

\section{Results}

\section{a. Low-level fluxes along the flight track}

Figure 4 and Table 4 indicate that model $H$ values have a significant high bias. Both coupled and uncoupled Noah LSM runs overestimate $H$ by about a factor of 2 for the dry-down sequence in June (Table 1). Modeled LE values are closer to observed, but still slightly large, resulting in a horizontally averaged available energy $(H+\mathrm{LE})$ between 100 and $150 \mathrm{~W} \mathrm{~m}^{-2}$ higher than observed. For 30 May, the discrepancies are larger but with a similar pattern, with modeled LE values closer to observations than the $H$ values.

While both the coupled and uncoupled Noah LSM runs show $H$ (LE) consistently increasing (decreasing) westward in both coupled and offline runs, the observations show large excursions on the $\sim 10-15-\mathrm{km}$ scale, especially for LE, with little evidence of an east-west trend. This is also true for 17 and 20 June, which have similar observed and modeled patterns (not shown). LeMone et al. (2007b) found that observed $H$ and LE respond strongly to NDVI and $T_{s}$, which were strongly correlated with vegetation type along the flight track. In contrast, Desai et al. (2006) found buoyancy fluxes better correlated with soil moisture along a north-northeast-south-southeas flight track across Oklahoma and Kansas during SGP-97.

Because the diversity in land cover along the track was lost in the aggregation process used to generate the model input tables (cf. Figs. 1 and 2), the observed vegetationrelated changes could not be captured by the Noah LSM. 
Model input soil texture is nearly uniform along the eastern track as well (Fig. 2). Thus, modeled $H$ and LE trends follow the modeled volumetric soil moisture trend in the model (Fig. 5): comparing Figs. 4 and 5, we see that the 30 May LE $(H)$ rises (falls) toward the east with the rise in volumetric soil moisture; while on 22 June a bump in soil moisture at the center of the track leads to a corresponding $H$ minimum and LE maximum superimposed on the east-west trend for the offline run. Since most of the points along the flight track, including those with high soil moisture, have the same soil type and vegetation cover, we suspect the bump is due to a local maximum in the measured precipitation used as input into HRLDAS.

From Fig. 5, the Noah LSM volumetric soil moisture values are lower than those observed. This is due at least in part to low stage IV rainfall estimates used in HRLDAS (Chen et al. 2007), as pointed out in LeMone et al. (2007b). It is difficult to draw any conclusions regarding horizontal patterns beyond a general moistening toward the east: the observations are too sparse to capture the soil moisture maximum for the coupled run, the two sets of soil moisture measurements on 30 May differ from one another, and the TRIME measurements show considerable scatter.

\section{b. The slope $\Delta \mathrm{LE} / \Delta H$}

For days with few or no clouds and large horizontal variability in $H$ and $\mathrm{LE}$, plots of time-averaged $\mathrm{LE}$ as a function of time-averaged $H$ for a given area tend to fall on a straight line with a negative slope. The amount of scatter about the line provides a measure of the quality of the sample (LeMone et al. 2003). The slope of the line is a measure of both the relative amplitudes of $H$ and LE horizontal variability (LeMone et al. 2008) and the horizontal variation of available energy $H+$ $\mathrm{LE}=R_{\text {net }}-G$, where $R_{\text {net }}$ is the net radiation, and $G$ is the flux into the soil (Alfieri et al. 2009). As illustrated by Fig. 6, points on $H$ versus LE plots from the Noah LSM run offline (as well as coupled for clear skies) typically fall on almost perfect straight lines for the eastern track, with negative slopes, consistent with the association of large $H$ with small $\mathrm{LE}$ and vice versa.

From Table 4, the model-produced slopes are too shallow compared to observations, an indication that the ratio of the model versus observed amplitudes of $H$ and LE variability varies with the ratio of their averages. Unfortunately, the data were sufficiently good (small enough measurement uncertainty, large enough horizontal variability in $H$ and LE; LeMone et al. 2003) to define a slope only for 30 May and 22 June, the days with the largest samples; these conditions were not satisfied on 17 and 20 June. The ability to produce a slope is a stringent test, however: $H$ and LE patterns on 17 and
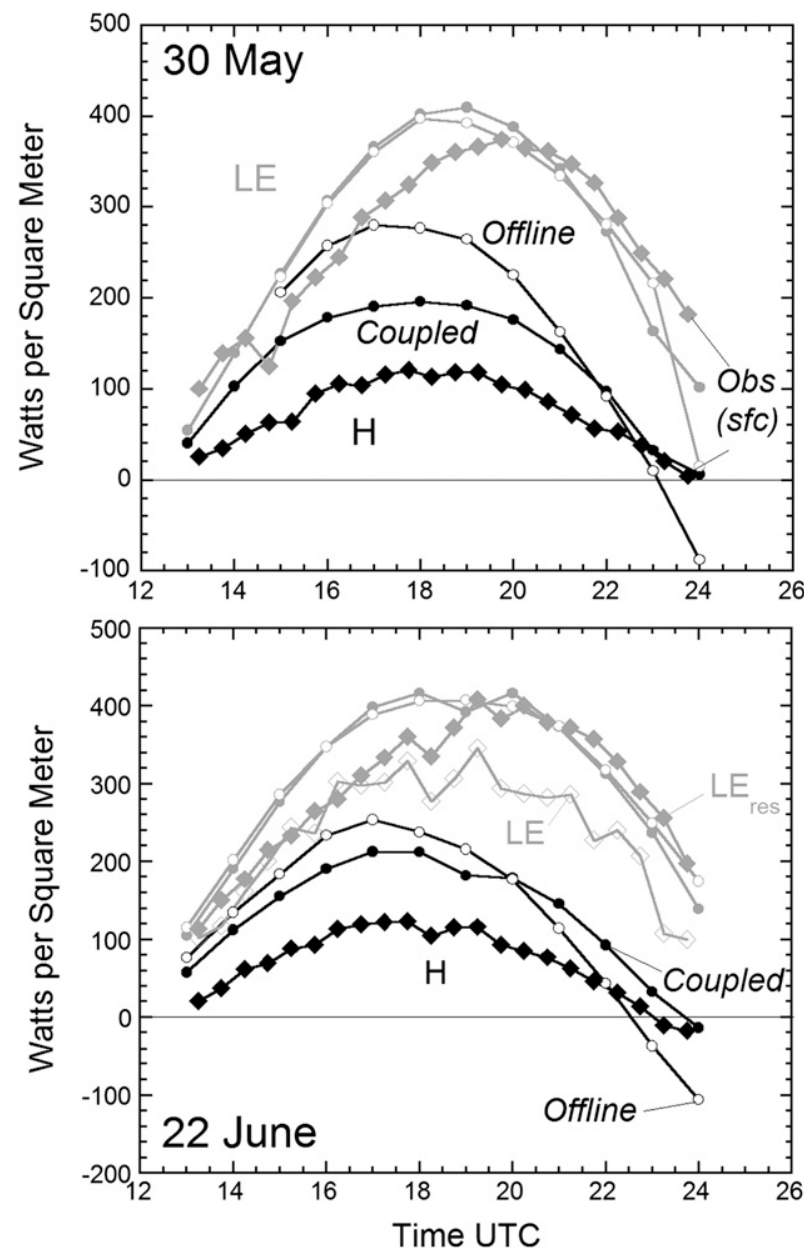

FIG. 7. Daytime variation of sensible and latent heat fluxes $H$ (black) and LE (gray) for 30 May and 22 Jun 2002. Noah LSM: solid circles $=$ coupled; open circles $=$ offline. Observations: $L_{\text {res }}$ (found as a residual from surface energy budget) = solid diamonds; LE (directly measured) = open diamonds. Note that coupled model surface fluxes were influenced by clouds on 22 Jun. Site 7 was not operating on 30 May, so observed $H$ is the average of sites 8 and 9. Local solar noon is about 1830 UTC.

20 June were similar to those on 30 May and 22 June, which in turn related to surface cover, $T_{s}$, and NDVI (LeMone et al. 2007b).

\section{c. Origins of the discrepancies}

To see whether discrepancies in $H, \mathrm{LE}$, and $\Delta \mathrm{LE} / \Delta H$ were related to the underestimates in soil moisture, we ran the Noah LSM offline for 30 May with soil moisture more like that observed (Fig. 5, triangles), for the grid points along the eastern track. Increasing soil moisture values lowered $H$ by only $\sim 50 \mathrm{~W} \mathrm{~m}^{-2}$, but raised LE by $100-150 \mathrm{~W} \mathrm{~m}^{-2}$ to artificially high values, and changed $\Delta \mathrm{LE} / \Delta H$ only slightly, from -1.26 (Fig. 6) to -1.32 .

An alternate explanation for the too-shallow modeled slope, based on the similarity of these discrepancies to 


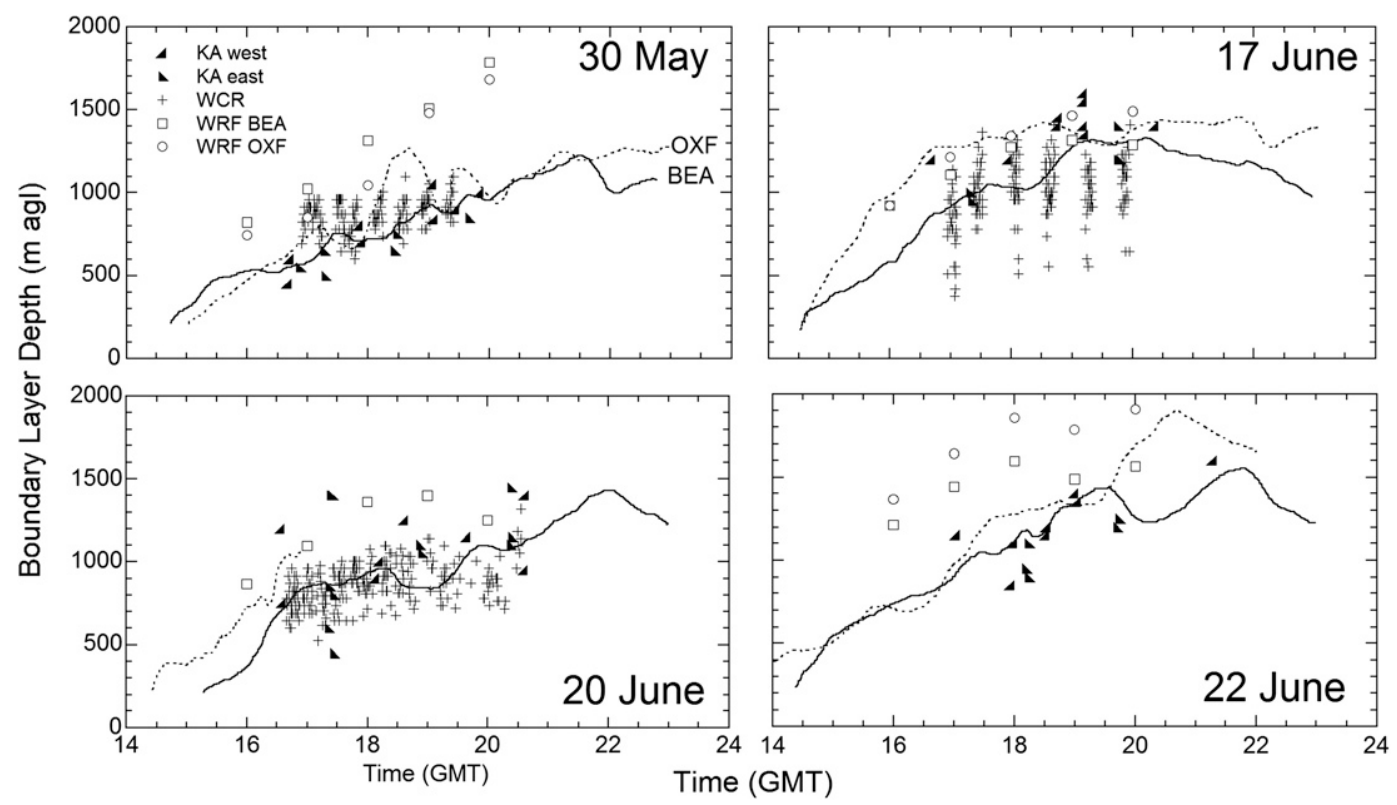

FIG. 8. For the four IHOP_2002 days, CBL depth as a function of time. Observations: from King Air leg-end soundings $\left(h_{\mathrm{KA}}\right.$, solid wedge triangles, pointing right for near the east end of the leg, and left for near the west end), the WCR $\left(z_{i \_ \text {WCR }},+\right)$, and the ABLE radar wind profilers $\left(z_{i \_ \text {Prof }}\right)$ at OXF (dotted line) and BEA (solid line). Model: $h_{\mathrm{WRF}}$ at Oxford $=$ open circles; $h_{\mathrm{WRF}}$ at Beaumont $=$ open squares.

those for 29 May on the western track, is that the default coefficient $C=0.1$ (used here) in the Zilitinkevich (1995) equation relating the roughness lengths for heat and momentum in the Noah LSM may be too small (LeMone et al. 2008). They found that raising $C$ from its default value of 0.1 to 0.5 produced a good match for $H$, $\mathrm{LE}, H+\mathrm{LE}$, and $\Delta \mathrm{LE} / \Delta H$. Using data from IHOP_2002, Gutmann (2008) used an inverse-modeling exercise to deduce values of $C$ between 0.17 and 0.99 .

We can get a rough estimate of $C$ along the eastern track for 17-22 June using the Zilitinkevich equation in the Noah LSM, namely:

$$
z_{0 H}=z_{0 M} \exp \left(-k C \sqrt{\frac{u_{*} z_{0 M}}{v}}\right),
$$

where $z_{0 H}$ and $z_{0 M}$ are respectively the grid-scale roughness lengths for heat and momentum, $u_{*}$ is the grid-scale friction velocity, $k=0.4$ is the von Kármán constant, $v$ is the kinematic molecular viscosity of air $\left(\sim 1.5 \times 10^{-5} \mathrm{~m}^{2} \mathrm{~s}^{-1}\right)$, and $C$ is an empirical coefficient, normally set to 0.1 based on comparing model results and field data (Chen et al. 1997). In (1), we use the aircraft-based regional (eastern track average) roughness values to be consistent with the default model roughness length for grass $(0.12 \mathrm{~m})$ and evidence that the model "sees" regional momentum fluxes (Strassberg et al. 2008, who note that the "regional" fluxes respond not only to grass, but to trees, houses, etc.) We use $z_{0 M}$
(0.14 m) and regional $u_{*}$ values from Strassberg et al. (2008). To obtain $z_{0 H}$, we apply (19) from Beljaars and Holtslag (1991, hereafter BH91), using local heat and momentum roughness length values $z_{0 h}$ and $z_{0 m}$ based on data from the surface flux towers (sited in this case such that fluxes respond to grasses), the Strassberg et al. value of $z_{0 m}$, and an estimate of blending height from (16) in BH91 with the distance to the nearest obstacle $L_{\mathrm{x}}=200 \mathrm{~m}$. Using the range of $z_{0 h}$ values obtained from the surface sites and $z_{0 m}=0.02 \mathrm{~m}$ in the BH91 equation (for a complete list of momentum roughness lengths derived from surface-site data, see online at http:// www.eol.ucar.edu/rtf/projects/ihop_2002/isff/), we obtain values of $z_{0 H}$ from $\sim 7 \times 10^{-5}$ to $1 \times 10^{-8} \mathrm{~m}$. From (1), this corresponds to a $C$ value between 0.27 and 0.59 . Using the blending heights derived from Strassberg et al. with the other values staying the same yields $C$ values ranging from 0.33 to 0.68 .

\section{d. Time variation of fluxes}

Figure 7 compares diurnal variation of observed surface $H$ and LE to coupled and offline model values, for 30 May and 22 June. The model overestimates of $H$ and to a lesser degree LE seen in Fig. 4 persist through the morning. However, by about 2000 UTC, observed LE found as a residual from the surface energy budget agrees better with modeled LE, and observed and modeled $H$ start to approach each other. Measured LE, 

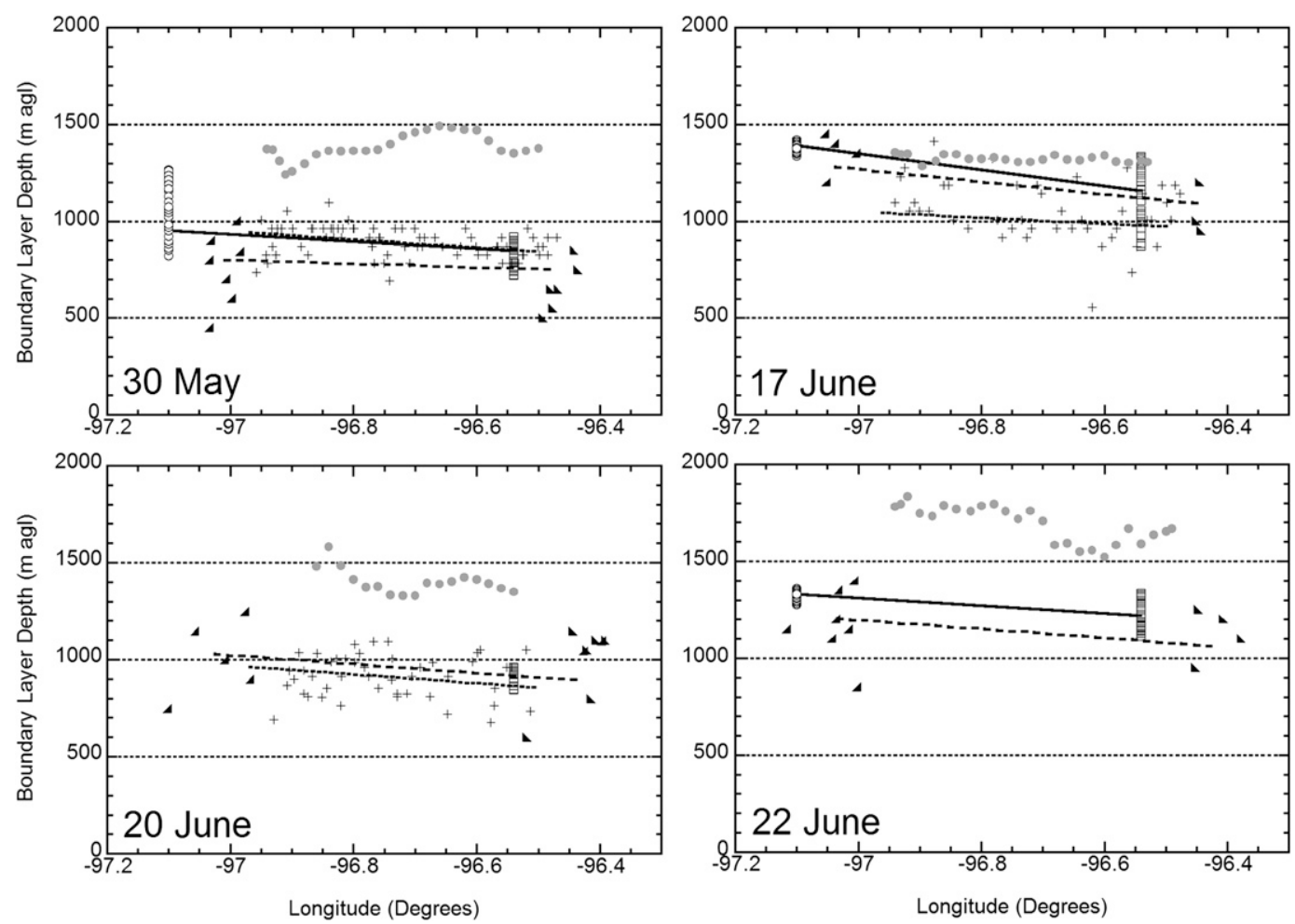

FIG. 9. Comparison of ARW-WRF to observed CBL depth, as a function of longitude along the eastern track at 1830 UTC ( local solar noon). Symbols as in Fig. 8, but for $h_{\mathrm{WRF}}=$ filled-in gray circles. OXF (west) and BEA (east) radar wind profiler CBL depths are shown for the duration of the flight pattern. ARW-WRF CBL depths are average of 1800 and 1900 UTC values. The straight lines connect CBL depths at points interpolated to 1830 UTC using least squares best-fit curves: solid lines connect $z_{i \_ \text {Prof }}$ values based on best-fit quadratics to depth time series; dotted lines connect $z_{i}$ WCR values, found as described in section $2 \mathrm{~d}$; and dashed lines connect $h_{\mathrm{KA}}$ values based on best-fit straight lines to time series of height estimates from King Air soundings near the ends of the leg.

available for sites 8 and 9 on 22 June, remains lower than the model values. By 2400 UTC, the offline value of $H$ becomes significantly negative. LeMone et al. (2008) associated the exaggerated $H$ from morning to early afternoon with too low a value of $C$ and the negative value at 2400 UTC with a half-hour offset in the input solar radiation so that sunset was a half-hour too early. ${ }^{2}$

\section{e. Convective boundary layer depth}

Figures 8 and 9 show the CBL depth as a function of time and longitude, respectively, based on observations and ARW-WRF. As noted in the foregoing, the wind profiler CBL depth $z_{i_{i} \text { Prof }}$ is based on an algorithm that identifies the CBL top as immediately beneath the maximum vertical SNR gradient, which typically occurs in the middle of the transition layer between the CBL and the free atmosphere; the WCR CBL depth $z_{i}$ WCR is

\footnotetext{
${ }^{2}$ The solar radiation data used as input for HRLDAS are advertised as having a 15-min offset; HRLDAS code assumes no time offset. For times near noon, even the half-hour offset had little effect in LeMone et al. (2008).
}

based on the insect-echo SNR dropoff; and the aircraftsounding CBL depth is the mixed-layer depth $h_{\mathrm{KA}}$. The aircraft soundings (Fig. 10) show that the differences between $h_{\mathrm{KA}}$ and $z_{i}$ Prof are related to the depth of the transition layer, with the smallest differences corresponding to the shallow transition layer on 17 June, and the largest differences corresponding to the deep transition layer on 22 June (Fig. 9).

The relationship of $z_{i_{-} \mathrm{WCR}}$ to $h_{\mathrm{KA}}$ and $z_{i_{-} \text {Prof }}$ is a function of CBL depth, with more consistent estimates for shallower CBLs, suggesting a relationship to how high the insects typically penetrate. On 30 May $\left(z_{i} \sim\right.$ $900 \mathrm{~m}$ at the center of the track at 1830 UTC, Table 1), $z_{i_{-} \mathrm{WCR}}=z_{i_{-} \mathrm{Prof}}$ and $z_{i_{-} \mathrm{WCR}}>h_{\mathrm{KA}}$ (lines, Fig. 9), as expected if insect plumes, like buoyant plumes, penetrate beyond the mean mixed-layer top. Likewise, the WCR provided accurate estimates of the $\sim 1-\mathrm{km}$ CBL depths along the IHOP_2002 western track on 29 May (Miao et al. 2006). However, $z_{i-\mathrm{WCR}}<h_{\mathrm{KA}}$ on 17 and 20 June (leg-center CBL depth at 1830 UTC $\sim 1250 \mathrm{~m}$, Table 1), and the WCR signal is too weak on 22 June (leg-center CBL depth at $1830 \mathrm{UTC} \sim 1260 \mathrm{~m}$ ) to estimate $z_{i_{-} \mathrm{WCR}}$. 

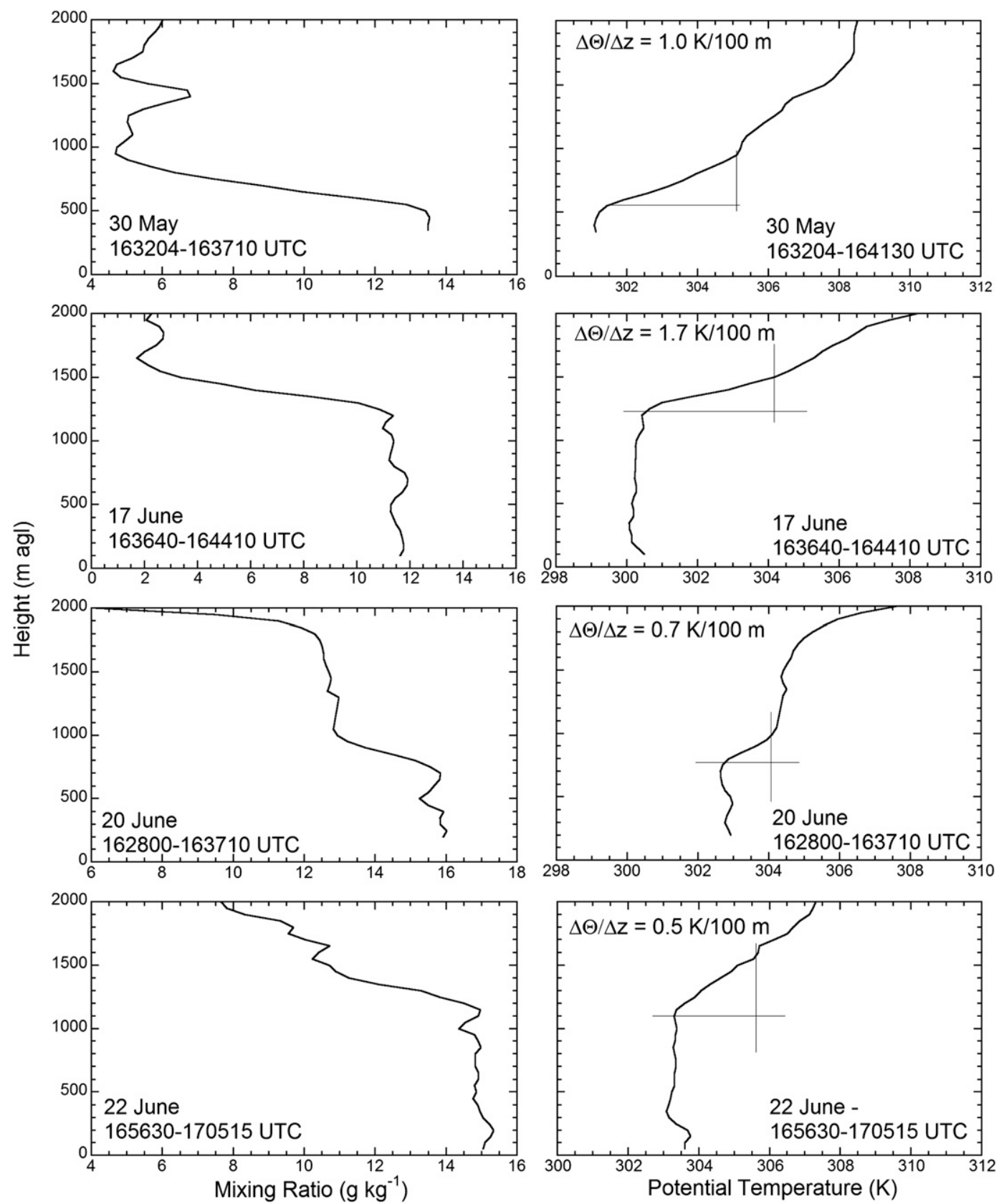

FIG. 10. Initial aircraft thermodynamic soundings for the four days examined. The indicated $\Theta$ gradient [1.0K $\left.(100 \mathrm{~m})^{-1}\right]$ is for the transition layer or the depth through which potential temperature and mixing ratio change more abruptly than above or below (denoted by thin lines intersecting the $\Theta$ profiles).

Note that the variability in $z_{i_{-} \mathrm{WCR}}$ and $h_{\mathrm{KA}}$ is considerably larger than that for $z_{i_{\perp} \text { Prof. }}$ The reason is that the first two are nearly instantaneous point measurements, while the profiler effectively averages over $\sim 6 \mathrm{~min}$ and a horizontal distance of $\sim 800 \mathrm{~m}$ at a 1-km height.

Wind (Table 1) could affect WCR signal strength and thus $z_{i-\mathrm{WCR}}$. The strongest signal and the weakest winds $\left(3.9 \mathrm{~m} \mathrm{~s}^{-1}\right)$ of the four IHOP_2002 days were on
30 May, and the weakest signal and the strongest winds $\left(9.4 \mathrm{~m} \mathrm{~s}^{-1}\right)$ were on 22 June. Similarly, the IHOP_2002 BLH flight on 29 May has low winds $\left(4.9 \mathrm{~m} \mathrm{~s}^{-1}\right.$; Miao et al. 2006) and a strong signal. Kusunoki (2002) found fewer echoes over the Kanto plain in Japan with stronger winds in summer, which he linked to a lack of insects. However, other factors are important as well: 20 June had weak winds $\left(5.3 \mathrm{~m} \mathrm{~s}^{-1}\right)$ but reflectivity almost as 

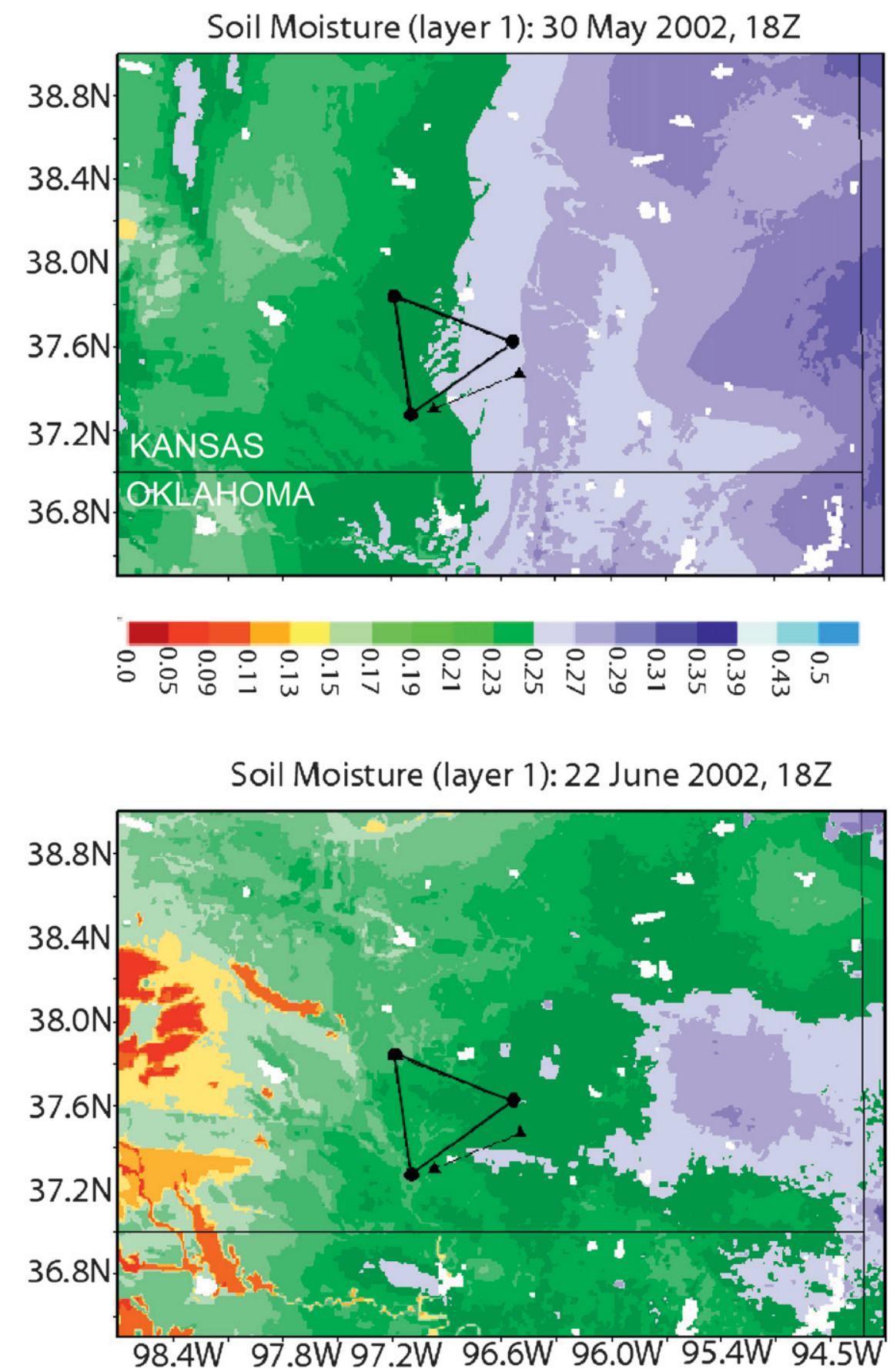

FIG. 11. Noah LSM volumetric soil moisture distribution for level $1(0-10 \mathrm{~cm})$ in d03 (Fig. 2) for coupled run, at 1800 UTC (top) 30 May and (bottom) 22 Jun. White areas represent open water. Profiler triangle and eastern track are superimposed.

low as 22 June, and 17 June had similar reflectivity to 30 May but stronger winds $\left(7.7 \mathrm{~m} \mathrm{~s}^{-1}\right)$. Jim Wilson (NCAR, 2007, personal communication) found no relationship of insect echo to wind speed during the day over the western track, and suggests that a relationship to wind could be site dependent.
All three observed CBL depth estimates in Fig. 9 show deepening toward the west end of the flight track on all four days, a trend followed in ARW-WRF except for 30 May. In each case, there are superimposed smallerscale fluctuations in PBL depth, which are associated with kilometer-scale CBL eddies. The east-west trend in 

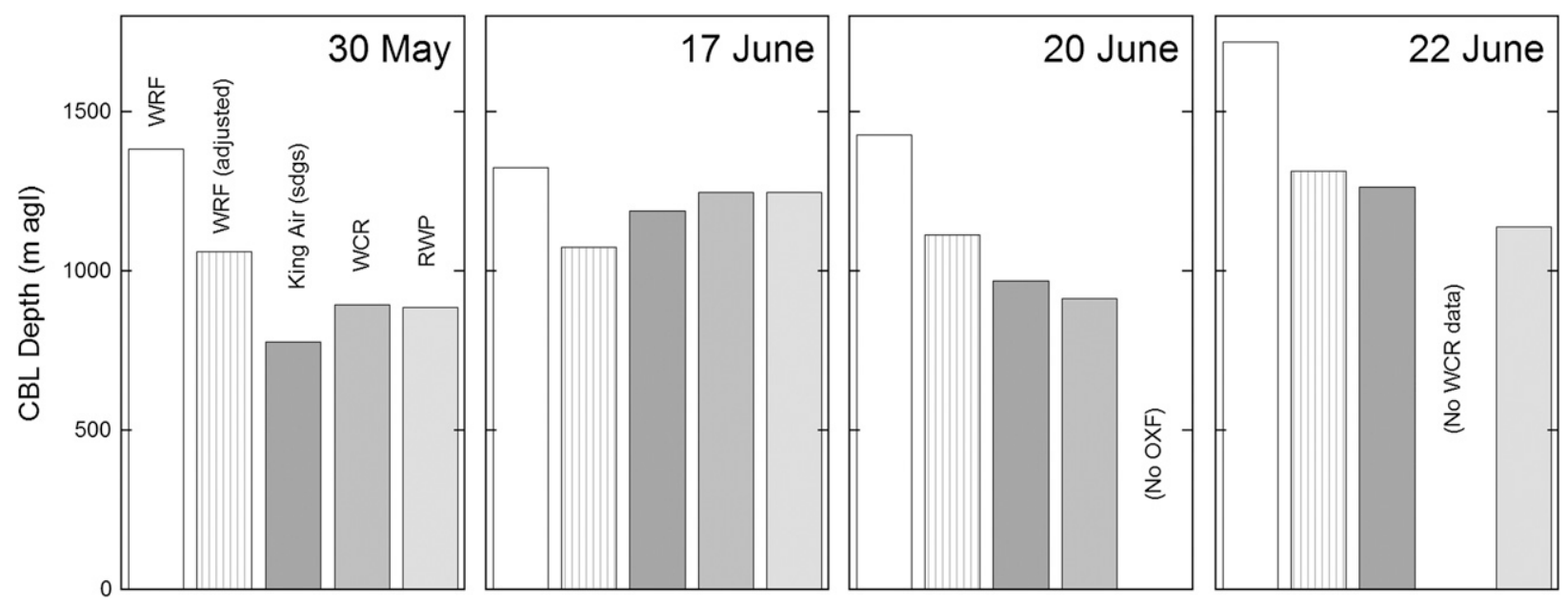

FIG. 12. Comparison of along-track CBL depths at 1830 UTC from ARW-WRF (raw, adjusted for the biases in ARW-WRF surface fluxes) to observed values.

CBL depth is consistent with the modeled upstream (southern) fetch with higher $H$ to the west, which is in turn consistent with drier soils (Figs. 5 and 11) and more winter wheat (senescent and then harvested) to the west (Figs. 1 and 2). In the observations, the $z_{i \text { WCR }}$ trend is consistent with the other two despite values being too low on some days. The association of the deepest CBL with the lowest terrain means that the horizontal variation in the CBL depth relative to mean sea level is less than the terrain variation along the flight track (Fig. 1).

In Figs. 8 and 9, the ARW-WRF CBL depths $h_{\mathrm{WRF}}$ are deeper than those observed, with large discrepancies except for 17 June. Multiple sensitivity studies (Table 3) showed that horizontally averaged $h_{\mathrm{WRF}}$ remained virtually unchanged with different grid sizes, the lack of soil moisture perturbations, domain depth, or horizontal filtering. However, no sensitivity studies were conducted to determine the potential impact of the $\sim 250$-m vertical grid spacing around $z=h_{\mathrm{WRF}}$ (section $3 \mathrm{c}$ ).

We believe most of the discrepancy is related to the high bias in $H$ (Figs. 4 and 7 and Table 4). For a wellmixed (constant $\Theta_{v}$ ) CBL in the absence of advection, for which virtual potential temperature flux $\overline{w \theta_{v}}$ varies linearly with height, with values at the surface (subscript 0 ) and $z_{i}$ (subscript $z i$ ) related via $\overline{w \theta}_{v i}=-\beta \overline{\left.w \theta v\right|_{0}}$, where $\beta$ is a constant ${ }^{3}$ Garratt (1992, p. 155) obtains the expression $\partial / \partial t\left(z_{i}^{2} / 2\right)=\left.\gamma^{-1}(1+2 \beta) \overline{w \theta_{v}}\right|_{0}$, where $\gamma$ is the

\footnotetext{
${ }^{3}$ Conzemius and Fedorovich (2006) suggest the relationship $\overline{w \theta_{v, z i}} \approx-0.2 \overline{w \theta_{v, 0}}$ applies if the shear at PBL top is small. Strassberg et al. (2008) found the shear to be small for the June days, and "small to moderate" for 30 May, with a $z_{i}$-to-surface flux ratio less than 0.2 , so the relationship should apply reasonably well for the 4 days discussed here.
}

vertical gradient of $\theta_{v}$ above the CBL. Thus, the depth of the CBL roughly varies as the square root of the integrated virtual temperature flux during the previous daytime hours, and the ARW-WRF boundary layer depth can be adjusted to allow for the $H$ discrepancy by multiplying by the square root of the ratio $\sum_{1300}^{1830} \frac{w T_{v}}{0, \text { obs }} /$ $\left.\sum_{1300}^{1830} w T_{v}\right|_{0, \mathrm{WRF}}$. Since ARW-WRF values are hourly, we find the denominator by averaging the sums from 1300-1800 UTC to 1300-1900 UTC. The adjusted CBL depths appear in Fig. 12. From the figure, we see that the adjusted ARW-WRF CBL depths are closer to observed, with the exception of 17 June, for which the observed CBL depth is bracketed by the corrected and uncorrected values.

Assuming that the too-high $H$ is related to too low a $C$ value, would raising $C$ improve $\mathrm{CBL}$ depth? At least in the ARW-WRF simulations of Trier et al. (2004), increasing $C$ from 0.1 value to 1.0 improved CBL depth and mixing ratios (S. Trier 2009, personal communication), although they used the Mellor-Yamada-Janjic (MYJ) PBL scheme. Model studies with adjusted $C$ values are needed to answer this question definitively.

\section{f. Horizontal variability and time trends of $\theta$ and $Q$}

Time-averaged 1-km averages of $\Theta$ and $Q$ along the flight track are shown for the 4 days along with corresponding model values in Fig. 13, with time trends of along-leg averages in Figs. 14 and 15. For the grandaverage leg (Fig. 13), differences between simulated and observed $\Theta$ and $Q$ are less than $1 \mathrm{~K}$ for $\Theta$ and $1 \mathrm{~g} \mathrm{~kg}^{-1}$ for $Q$. Comparison of the input data near the surface suggests the large 30 May $\theta$ bias is at least partially related to too-high values used to initialize ARW-WRF at 1200 UTC, as well as too-high $H$. Likewise, too-high $Q$ 

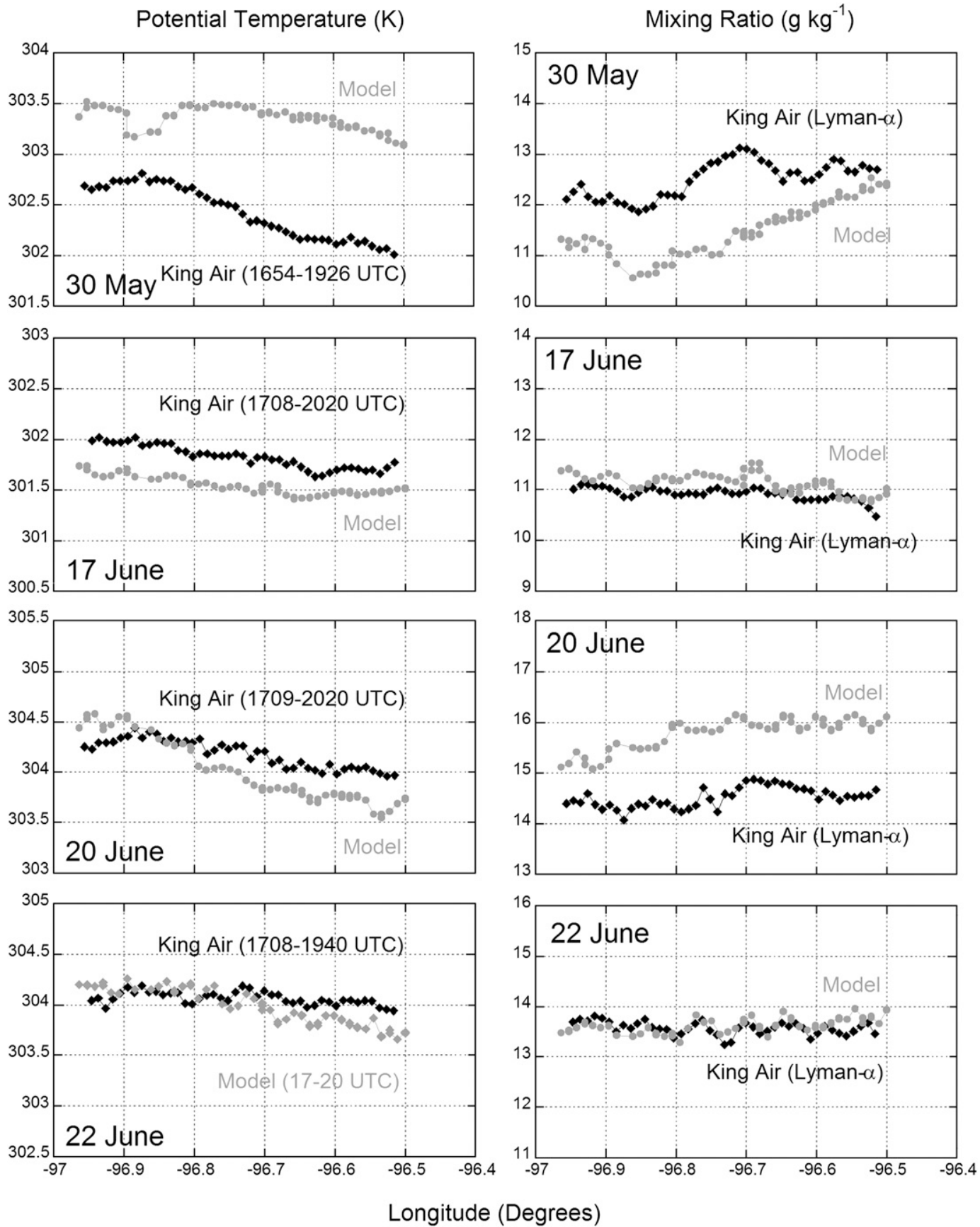

FIG. 13. Space $(1 \mathrm{~km})$ and time-averaged (left) $\Theta(\mathrm{K})$ and (right) $Q\left(\mathrm{~g} \mathrm{~kg}^{-1}\right)$ along the eastern track at $\sim 65 \mathrm{~m}$ AGL for all four fair weather days, compared to ARW-WRF values at the same heights. ARW-WRF values average of 1700-2000 UTC; King Air times are beginning of first leg and end of last leg in average. Note that last three low-level legs are not included in 22 Jun average.

on 20 June could be linked to a high bias at initialization. However, on 30 May, ARW-WRF predicts too low a $Q$ value, in spite of a too-high initial $Q$ near the surface, possibly related to exaggerated CBL growth. Unfortunately, a rigorous comparison requires more data than are available.
In Fig. 13, $\Theta$ shows an east-west gradient for both model and observations, while $Q$ has a variable pattern, with horizontal variability varying from small for 22 June to significant for 30 May in both model and observations. Of the 4 days, the observed $\Theta$ gradient is strongest for 30 May and weakest for 22 June. These two 
Potential Temperature (K)
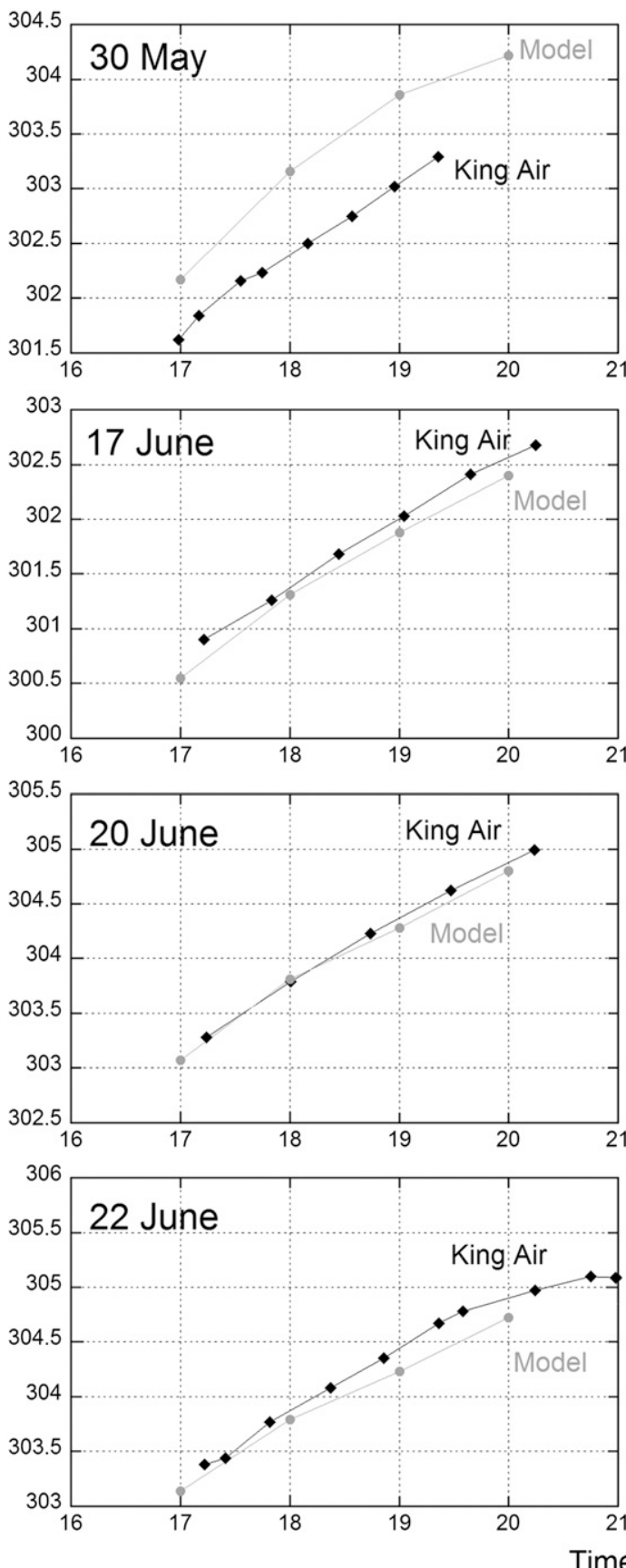

Time
Mixing Ratio $\left(\mathrm{g} \mathrm{kg}^{-1}\right)$
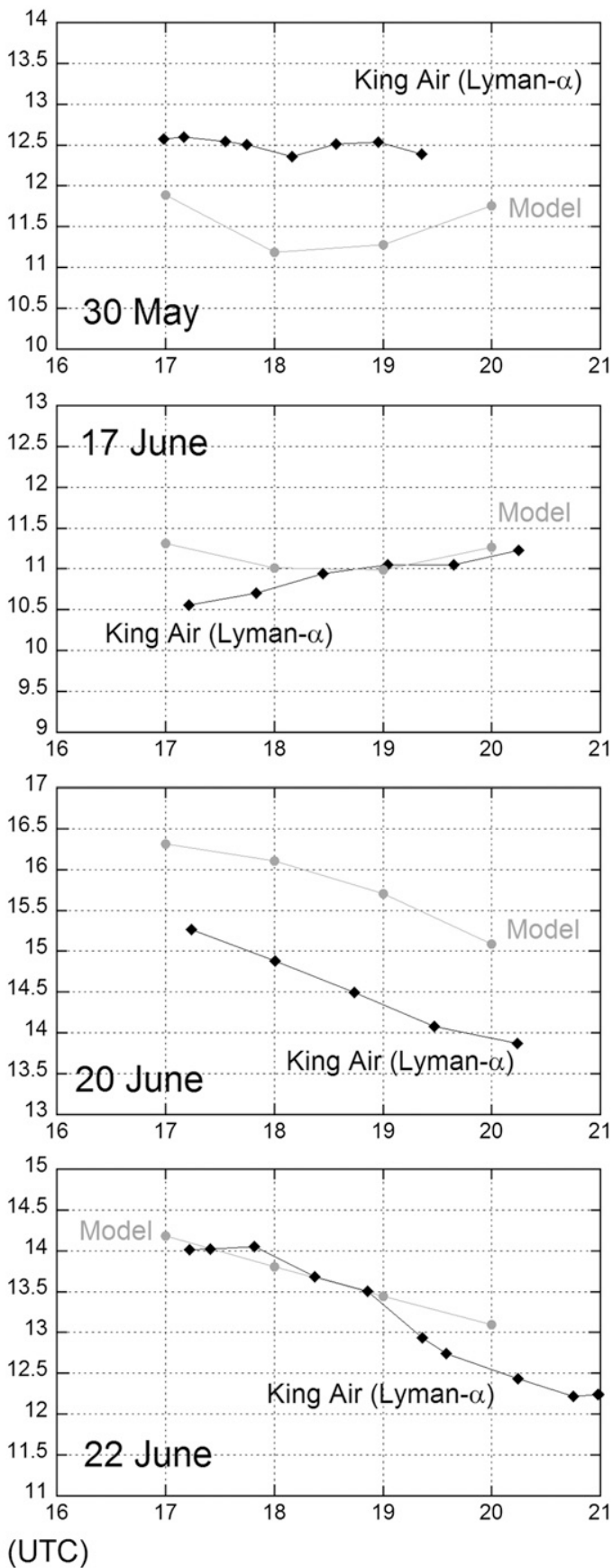

FIG. 14. Trends for leg-averaged $\Theta(\mathrm{K})$ and $Q\left(\mathrm{~g} \mathrm{~kg}^{-1}\right)$ at $\sim 65 \mathrm{~m} \mathrm{AGL}$.

extremes are consistent with the simulated volumetric soil moisture patterns in Fig. 11, which show strong contrast along and upstream (south) of the flight track on 30 May, but not much change on 22 June. Aircraft observations reveal that a similar $\Theta_{v}$ gradient extends through the mixed layer on all 4 days. The source of this gradient will be explored further in Part II.
The $Q$ evolution (Fig. 14) varies from day to day in response to the balance among surface fluxes, entrainment, and horizontal advection. On average, model trends are similar to observed trends in spite of too deep a modeled PBL, partially because of the compensating effect of too-high modeled LE (Table 4). On 20 and 22 June, $Q$ decreases with time, suggesting drying by 


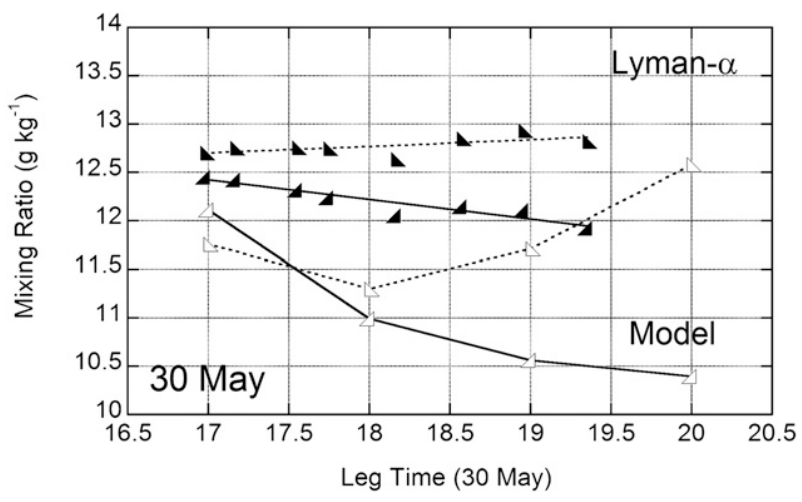

FIG. 15. As in Fig. 14, but to contrast $Q\left(\mathrm{~g} \mathrm{~kg}^{-1}\right)$ evolution along the east and west portions of the eastern track for 30 May. "Wedge" triangles pointing right and dashed lines indicate horizontally averaged $Q$ along track east of $-96.5^{\circ}$; wedge triangles pointing left and solid lines indicate horizontally averaged $Q$ along track west of $-96.5^{\circ}$; closed triangles for Lyman $\alpha$ on the King Air (separate points for each flight leg); open triangles for model.

entrainment of drier air from above the growing CBL dominates. On 17 June and 30 May, observed $Q$ varies little, indicating a near balance. However, $Q$ on 30 May decreases with time along the western half of the flight track, and increases slightly along the eastern half (Fig. 15). Given the dry air above the CBL $\left(Q \approx 6 \mathrm{~g} \mathrm{~kg}^{-1}\right.$, Fig. 10), part of the observed difference is likely related to faster CBL growth to the west (Fig. 9). Remarkably, ARWWRF produces similar trends after 1800 UTC. Warming rates (Fig. 14) are well replicated for 3 of the 4 days, and exaggerated slightly on 30 May. This is qualitatively consistent with offsetting effects of too-high $H$ (and presumably too-high entrainment flux) being mixed into too deep a CBL.

\section{g. Cloudiness over the eastern track}

To identify cloudiness along the eastern track, we used departures in $R_{\text {net }}$ from its clear-sky sinusoidal pattern at each of the surface sites, and departures from the straight line in plots of LE as a function of $H$ that is typical of ARW-WRF results for clear skies. Figure 16 illustrates the effect of clouds on $H$ and LE in ARWWRF. While the fluxes show an east-west trend, there are sharp excursions (represented by white points) that do not affect the available energy significantly, so that these points lie along the slope line on the $H$ versus LE plot. These points are associated with land use or soil types that differ from those for the majority of the points (e.g., grassland, silty clay loam). Clouds, however, reduce the available energy $H+$ LE significantly, and produce large excursions from the slope line. Such an abrupt decrease would not be observed, since the small clouds (evident in the satellite images discussed in Part II) would not be continuously present over the 0.5 -h flux-averaging time. Similarly, such abrupt changes would be eliminated from the aircraft fluxes by time and space averaging.

For 20 and 22 June, the timing of scattered clouds in model and observations was about the same (Fig. 17), in spite of differences in boundary layer depth. Likewise, the sky remained essentially cloudless in both the observations and simulations during the King Air flights on 30 May. On 17 June, the model failed to produce the observed clouds.

While the modeled slope $\Delta \mathrm{LE} / \Delta H$ is not affected by filtering in cloudless simulations, this is not the case when clouds are present, as illustrated by Fig. 18 (top). In the same way, clouds are probably the reason for the
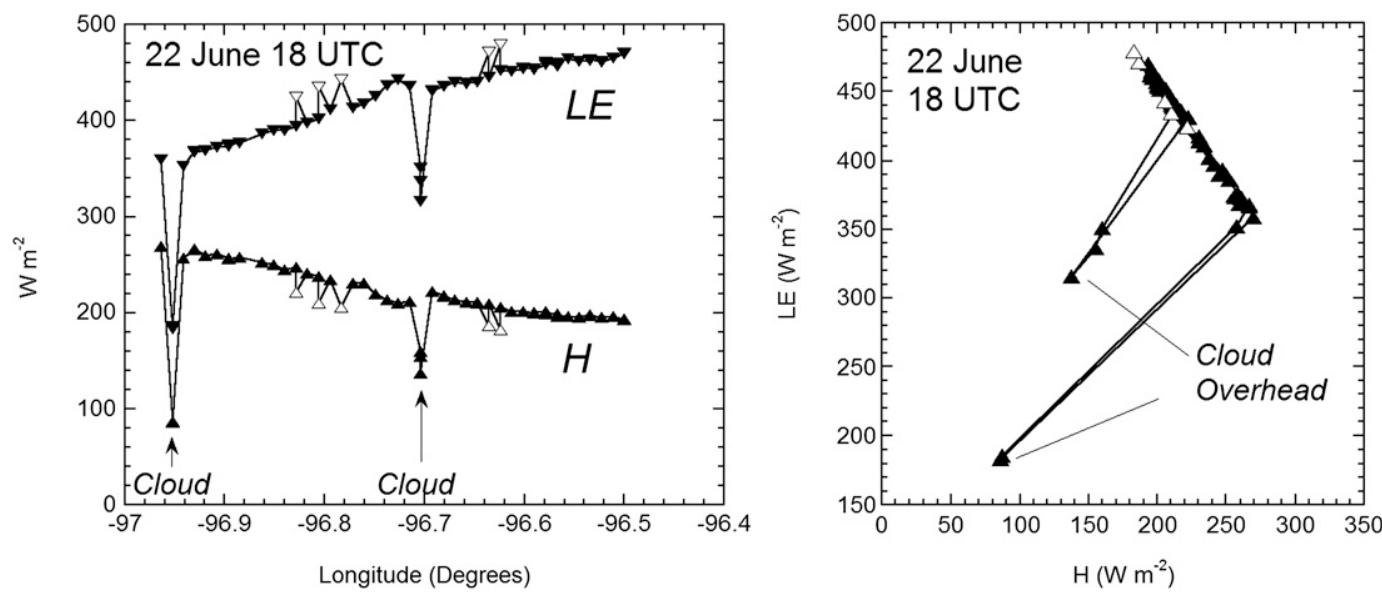

FIG. 16. Determining presence of clouds in ARW-WRF from their effects on the surface fluxes $H$ and LE. Open triangles: points with soil or vegetation different from that typical for the flight track (silty clay loam, grassland). The data here are full resolution; with more than one datum where an observation along the flight track was close to more than one model grid point. In left frame, arrows indicate clouds overhead. 

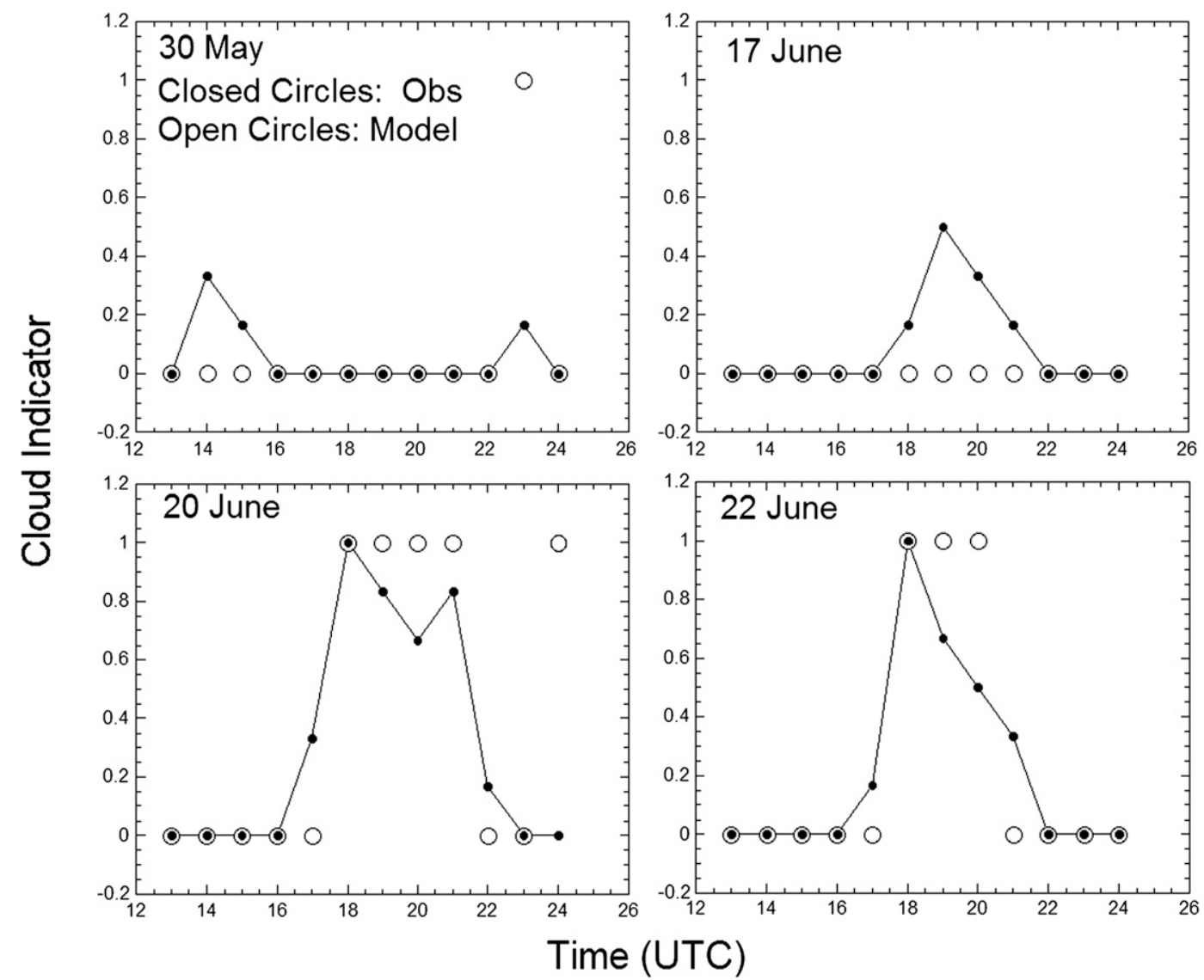

FIG. 17. Comparison of cloud occurrence in ARW-WRF to clouds detected at the three surface flux sites as a function of time. For ARW-WRF (open circles), each hour was assigned a value of " 0 " for no clouds along the eastern track, and " 1 " for one or more points with cloud along the track. For the observations (small, closed circles, connected by lines), each hour at a surface site was assigned " 0 " for a value corresponding to a clear-sky $R_{\text {net }}$ curve, " 0.5 " if there was a slight dip from the clear-sky value, or " 1 " if there was significant departure; and the average for the three surface sites was plotted.

need for a larger than 4-km filter length to obtain a stable slope for the observed fluxes on 22 June (Fig. 18, bottom). In contrast, for nearly-clear sky days like 29 May on the western track (LeMone et al. 2008) and 30 May on the eastern track (LeMone et al. 2007b), the observed slope reaches a stable value with about a $4-\mathrm{km}$ filter. As noted in these two papers, a 4-km filter eliminates most of the effect of flux concentration by CBL-scale eddies (up to 2-3 $z_{i}$ ). However, the slope converged more rapidly for the 22 June fluxes from the coupled Noah LSM than for the observations, probably because of fewer clouds in the simulation than observed.

\section{Conclusions}

Compared to observations along the IHOP_2002 eastern track in southeast Kansas on 4 fair-weather days with southerly winds and nearly clear skies, ARW-WRF replicates the occurrence of cumulus on 3 of the 4 days, as well as the influence of soil moisture on the horizontal variation of $\Theta$ and $Q$, and CBL depth. On the other hand, the model significantly overestimates $H$ and, as a consequence, CBL depth. Furthermore, the horizontal variability in $H$ and LE, which is highly correlated with vegetation patterns through NDVI and $T_{s}$ (LeMone et al. 2007b), bears little resemblance to that produced by the Noah LSM, and volumetric soil moisture is underestimated.

The Noah LSM provides a consistent picture of an east-west gradient in fluxes along the eastern track associated with moister soils to the east, with $H$ (LE) increasing (decreasing) westward, but not the observed variation, which is associated with land cover. Such behavior contrasts to that observed by Desai et al. (2006), who attributed most of the horizontal variability in buoyancy fluxes along the SGP-97 flight track across Oklahoma and Kansas to soil moisture. It is not surprising that the peaks and valleys in $H$ and LE associated 

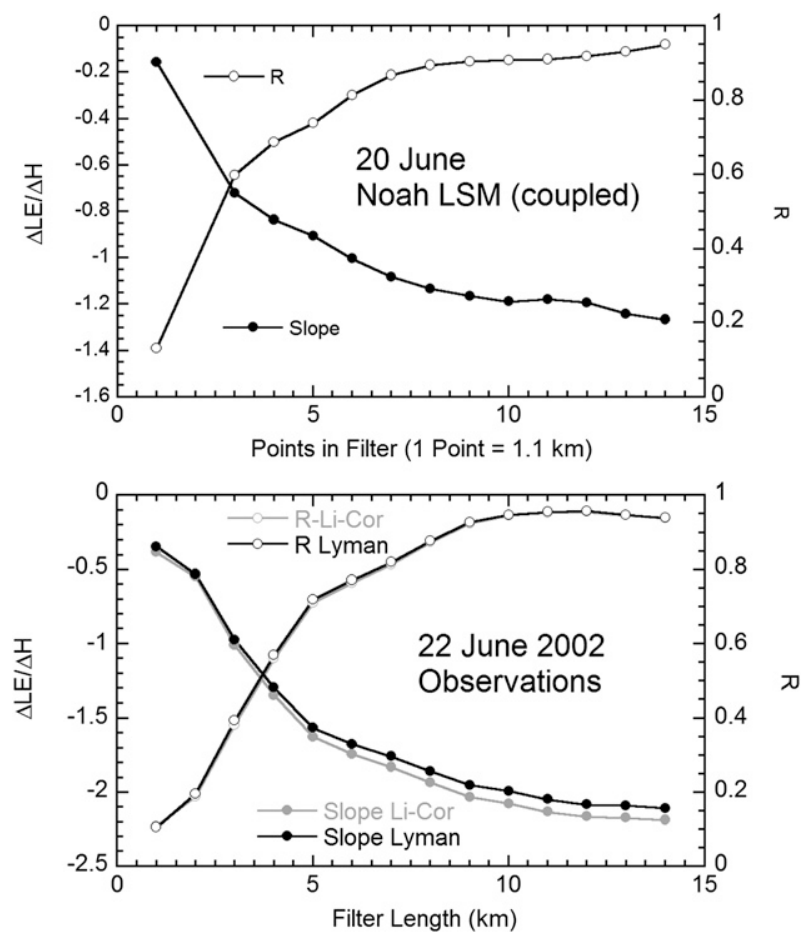

FIG. 18. In the presence of clouds, effect of filtering on slope $\Delta \mathrm{LE} / \Delta H$, for points along the flight track: (top) 20 Jun modeled fluxes averaged at 1700-2000 UTC, (bottom) 22 Jun observed fluxes averaged at 1700-2100 UTC. $R$ is the absolute value of the correlation coefficient for the least squares best-fit slope line.

with the horizontal distribution of grasses (green) and winter wheat (senescent by 30 May, harvested by 17 June) were not replicated, since the input land-use data along the track was almost entirely grassland (cf. Figs. 1 and 2).

Mean modeled LE values compared reasonably well with aircraft observations, but modeled $H$ was too high. The $H$ discrepancy could be partially due to too-low precipitation that translated into too-dry soils used in the initialization; but a rerun of the Noah LSM offline with volumetric soil close to observations improved $H$ only slightly while overestimating LE significantly. The $H$ discrepancy probably results primarily from too low a value of the coefficient $C$ in Zilitinkevich's formulation used in relating the roughness lengths for heat and momentum in the Noah LSM. Our estimates based on observations suggest a $C$ value in the range $\sim 0.26-$ 0.66 . Also, raising $C$ from its default value of 0.1 to something higher might improve the modeled $\Delta \mathrm{LE} / \Delta H$ slope: in LeMone et al. (2008), raising $C$ to 0.5 improved $H, T_{s}$, and $\Delta \mathrm{LE} / \Delta H$ to close-to-observed values for the western track for 29 May 2002.

A simple calculation suggests the overprediction of the modeled CBL depth $h_{\mathrm{WRF}}$ is related to the overestimate of $H$. If we attribute the high $H$ to too low a value of $C$, this is consistent with the results of Trier et al. (2004), who found improved $h_{\mathrm{WRF}}$ when $C$ was increased from 0.1 to 1.0 in their ARW-WRF simulations using the MYJ PBL scheme (S. Trier 2009, personal communication). Moreover, multiple sensitivity tests revealed that CBL depth was not affected by grid size, or the absence of soil moisture or $T_{s}$ perturbations.

The discrepancies between observed and modeled $H$ and LE change with time. Most remarkably, $H$ is strongly negative at 2400 UTC for the offline Noah LSM runs, a function of a half-hour time shift in input solar radiation. This behavior was reported for the western track in LeMone et al. (2008).

Modeled horizontal trends in $\Theta$ and $Q$ were reasonably reproduced; but the average magnitudes differed by values up to $1 \mathrm{~K}$ and $1 \mathrm{~g} \mathrm{~kg}^{-1}$. Some magnitude discrepancies can be traced to biases in initial conditions (the model was initialized only $5 \mathrm{~h}$ before the beginning of the comparison time) or the overestimate of CBL depth. However, the too-deep CBL allowed dilution of the heat and moisture accumulation associated with toohigh surface fluxes and engulfment of too much warm, dry air from above to keep the trends in $\Theta$ and $Q$ similar.

Taken together, the results of this work indicate two needed next steps in the use of LSMs in ARW-WRF. First, (specific to the Noah LSM), this paper adds to the accumulating evidence that adjustment of the Zilitinkevich coefficient will improve surface fluxes. However, the work of Chen and Zhang (2009) indicates that the needed $C$ adjustments vary with land cover. Once this dependence is worked out, ARW-WRF runs can be made incorporating this new option. Second, because of the sharply contrasting timing of the life cycles of grassland and winter wheat (and presumably other vegetation as well), simply not accounting for the minority land cover in grid boxes introduces significant error over the region investigated. This problem can be dealt with in a straightforward way by allowing for more than one land-cover type in each grid cell and averaging the derived properties that interact with the atmosphere. Once these steps are completed, we can focus more closely on the behavior of the PBL schemes and their shortcomings.

Acknowledgments. This work would not have been possible without the commitment, enthusiasm, and expertise of the Wyoming King Air aircrew, the staff maintaining the Wyoming Cloud Radar, the National Center for Atmospheric Research (NCAR) staff maintaining the surface flux instruments, and the students taking the manual observations at the flux sites. We gratefully acknowledge Stan Trier of NCAR for reviewing the manuscript, and George Bryan and Chin-Hoh 
Moeng for giving us advice on model sensitivity tests, and four reviewers whose detailed comments greatly improved the text and figures. The NCAR portion of this research was supported by USWRP Grant NSF 01, the NCAR Water Cycle Initiative, and NASA THP (Dr. J. Entin NNG06GH17G). RLG's participation in IHOP_2002 was supported by NSF Grant ATM-0296159. RC's work was supported by the U.S. Department of Energy, Office of Biological and Environmental Research, under Contract W-31-109-Eng-38.

\section{REFERENCES}

Alfieri, J. G., D. Niyogi, H. Zhang, M. LeMone, and F. Chen, 2009: Quantifying the spatial variability of surface fluxes using data from the 2002 International $\mathrm{H}_{2} \mathrm{O}$ Project. Bound.-Layer Meteor., 133, 323-341, doi:10.1007/s10546-009-9406-2.

Anthes, R. A., 1984: Enhancement of convective precipitation by mesoscale variations in vegetative covering in semiarid regions. J. Climate Appl. Meteor., 23, 541-554.

Beljaars, A. C. M., and A. A. M. Holtslag, 1991: Flux parameterization over land surfaces for atmospheric models. J. Appl. Meteor., 30, 327-341.

Chen, F., and J. Dudhia, 2001: Coupling an advanced land surface hydrology model with the Penn State-NCAR MM5 modeling system. Part I: Model implementation and sensitivity. Mon. Wea. Rev., 129, 569-585.

— land surface and the atmosphere. Geophys. Res. Lett., 36, L10404, doi:10.1029/2009GL037980.

_ - Z. Janjic, and K. Mitchell, 1997: Impact of atmospheric surface layer parameterizations in the new land-surface scheme of the NCEP mesoscale Eta numerical model. Bound.-Layer Meteor., 85, 391-421.

_- R. Pielke Sr., and K. Mitchell, 2001: Development and application of land-surface models for mesoscale atmospheric models: Problems and promises. Observation and Modeling of Land Surface Hydrological Processes, V. Lakshmi, J. Albertson, and J. Schaake, Eds., Amer. Geophys. Union, 107-135.

—, D. N. Yates, H. Nagai, M. LeMone, K. Ikeda, and R. Grossman, 2003: Land surface heterogeneity in the Cooperative Atmosphere Surface Exchange Study (CASES-97). Part I: Comparing modeled surface flux maps with surface-flux tower and aircraft measurements. J. Hydrometeor., 4, 196-218.

_ - and Coauthors, 2007: Description and evaluation of the NCAR High-Resolution Land Data Assimilation System during IHOP_2002. J. Appl. Meteor. Climatol., 46, 694-713.

Conzemius, R. J., and E. Fedorovich, 2006: Dynamics of sheared convective boundary layer entrainment. Part I: Methodological background and large-eddy simulations. J. Atmos. Sci., 63, 1151-1178.

Coulter, R. L., and D. Holdridge, 1998: A procedure for the automatic estimation of mixed layer height. Proc. Eighth Atmospheric Radiation Measurement (ARM) Program Science Team Meeting, Tucson, AZ, Dept. of Energy Office of Energy Research, 177-180.

Couvreux, F., F. Guichard, P. Austin, and F. Chen, 2009: Nature of the mesoscale boundary layer height and water vapor variability observed on 14 June 2002 during the IHOP_2002 campaign. Mon. Wea. Rev., 137, 414-432.
Davis, C., and Coauthors, 2008: Prediction of landfalling hurricanes with the Advanced Hurricane WRF model. Mon. Wea. Rev., 136, 1990-2005.

Desai, A. R., K. J. Davis, C. J. Senff, S. Ismail, E. V. Browell, D. R. Stauffer, and B. P. Reen, 2006: A case study on the effects of heterogeneous soil moisture on mesoscale boundary-layer structure in the southern Great Plains, U.S.A. Part I: Simple prognostic model. Bound.-Layer Meteor., 119, 195-238.

Dudhia, J., 1989: Numerical study of convection observed during the winter monsoon experiment using a mesoscale twodimensional model. J. Atmos. Sci., 46, 3077-3107.

Ek, M. B., K. E. Mitchell, Y. Lin, E. Rogers, P. Grummann, V. Koren, G. Gayno, and J. D. Tarpley, 2003: Implementation of Noah land surface model advances in the National Center for Environmental Prediction operational mesoscale Eta model. J. Geophys. Res., 108, 8851, doi:10.1029/2002JD003296.

Fulton, R. A., J. P. Breidenbach, D.-J. Seo, D. A. Miller, and T. O'Bannon, 1998: The WSR-88D rainfall algorithm. Wea. Forecasting, 13, 377-395.

Garratt, J. R., 1992: The Atmospheric Boundary Layer. Cambridge University Press, $316 \mathrm{pp}$.

Geerts, B., and Q. Miao, 2005: The use of millimeter Doppler radar echoes to estimate vertical air velocities in the fairweather convective boundary layer. J. Atmos. Oceanic Technol., 22, 225-246.

Grossman, R. L., D. Yates, M. A. LeMone, M. L. Wesely, and J. Song, 2005: Observed effects of horizontal radiative surface temperature variations on the atmosphere over a Midwest watershed during CASES 97. J. Geophys. Res., 110, D06117, doi:10.1029/2004JD004542.

Gutman, G., and A. Ignatov, 1997: Satellite-derived green vegetation fraction for the use in numerical weather prediction models. Adv. Space Res., 19 (3), 477-480.

Gutmann, E. D., 2008: The determination of soil hydraulic properties in land surface models from remotely sensed surface temperature. Ph.D. dissertation, University of Colorado, Boulder, $128 \mathrm{pp}$.

Hong, S.-Y., Y. Noh, and J. Dudhia, 2006: A new vertical diffusion package with an explicit treatment of entrainment processes. Mon. Wea. Rev., 134, 2318-2341.

Klazura, G., and Coauthors, 2006: Atmospheric boundary layer measurements in south-central Kansas, 1997-2004. Bull. Amer. Meteor. Soc., 87, 1319-1324.

Knievel, J. C., G. H. Bryan, and J. P. Hacker, 2007: Explicit numerical diffusion in the WRF model. Mon. Wea. Rev., 135, 3808-3824.

Kusunoki, K., 2002: A preliminary survey of clear-air echo appearances over the Kanto Plain in Japan from July to December 1997. J. Atmos. Oceanic Technol., 19, 1063-1072.

LeMone, M. A., and Coauthors, 2000: Land-atmosphere interaction research, early results, and opportunities in the Walnut River watershed in southeast Kansas: CASES and ABLE. Bull. Amer. Meteor. Soc., 81, 757-779.

_ R. L. Grossman, F. Chen, K. Ikeda, and D. Yates, 2003: Choosing the averaging interval for comparison of observed and modeled fluxes along aircraft transects over a heterogeneous surface. J. Hydrometeor., 4, 179-195.

, and Coauthors, 2007a: NCAR/CU surface, soil, and vegetation observations during the IHOP_2002 field campaign. Bull. Amer. Meteor. Soc., 88, 65-81.

, F. Chen, J. G. Alfieri, M. Tewari, B. Geerts, Q. Miao, R. L. Grossman, and R. L. Coulter, 2007b: Influence of land cover and soil moisture on the horizontal distribution of 
sensible and latent heat fluxes in southeast Kansas during IHOP_2002 and CASES-97. J. Hydrometeor., 8, 68-87.

, M. Tewari, F. Chen, J. G. Alfieri, and D. Niyogi, 2008: Evaluation of the Noah land surface model using data from a fair-weather IHOP_2002 day with heterogeneous surface fluxes. Mon. Wea. Rev., 136, 4915-4941.

, F. Chen, M. Tewari, J. Dudhia, B. Geerts, Q. Miao, R. L. Coulter, and R. L. Grossman, 2010: Simulating the IHOP 2002 fair-weather CBL with the WRF-ARW-Noah modeling system. Part II: Structures from a few kilometers to $100 \mathrm{~km}$ across. Mon. Wea. Rev., 138, 745-764.

Lin, Y.-L., R. D. Farley, and H. D. Orville, 1983: Bulk parameterization of a snow field in a cloud model. J. Climate Appl. Meteor., 22, 1065-1092.

Mann, J., and D. H. Lenschow, 1994: Errors in airborne flux measurements. J. Geophys. Res., 99 (D7), 14 519-14 526.

Miao, Q., B. Geerts, and M. A. LeMone, 2006: Vertical velocity and buoyancy characteristics of coherent echo plumes in the convective boundary layer, determined by profiling airborne radar. J. Appl. Meteor. Climatol., 45, 838-855.

Mlawer, E. J., S. J. Taubman, P. D. Brown, M. J. Iacono, and S. A. Clough, 1997: Radiative transfer for inhomogeneous atmospheres: RRTM, a validated correlated-k model for the longwave. J. Geophys. Res., 102 (D14), 16 663-16 682.

Pazmany, A., R. McIntosh, R. Kelly, and G. Vali, 1994: Airborne $95 \mathrm{GHz}$ dual-polarized radar for cloud studies. IEEE Trans. Geosci. Remote Sens., 32, 731-739.

Pielke, R. A., G. Dalu, J. Snook, T. Lee, and T. Kittel, 1991: Nonlinear influence of mesoscale land use on weather and climate. J. Climate, 4, 1053-1069.

Pinker, R. T., I. Laszlo, J. D. Tarpley, and K. Mitchell, 2002: Geostationary satellite parameters for surface energy balance. $A d v$. Space Res., 30, 2427-2432.

Reen, B. P., D. R. Stauffer, K. J. Davis, and A. R. Desai, 2006: A case study on the effects of heterogeneous soil moisture on mesoscale boundary-layer structure in the southern Great Plains, U.S.A. Part II. Mesoscale modelling. Bound.-Layer Meteor., 120, 275-314.

Santanello, J. A., M. A. Friedl, and M. B. Ek, 2007: Convective planetary boundary layer interactions with the land surface at diurnal time scales: Diagnostics and feedbacks. J. Hydrometeor., 8, 1082-1097.
Segal, M., R. Avissar, M. McCumber, and R. Pielke, 1988: Evaluation of vegetation effects on the generation and modification of mesoscale circulations. J. Atmos. Sci., 45, 2268-2292.

Sellers, P. J., F. G. Hall, G. Asrar, D. Strebel, and R. Murphy, 1992: An overview of the First International Satellite Land Surface Climatology Project (ISLSCP) Field Experiment (FIFE). J. Geophys. Res., 97 (D17), 18 345-18 371.

Skamarock, W. C., J. B. Klemp, J. Dudhia, D. O. Gill, D. M. Barker, W. Wang, and J. G. Powers, 2005: A description of the Advanced Research WRF version 2. NCAR Tech. Note TN$468+$ STR, 88 pp. [Available from NCAR, P. O. Box 3000, Boulder, CO 80307.]

Stokes, G. M., and S. E. Schwartz, 1994: The Atmospheric Radiation Measurement (ARM) program: Programmatic background and design of the cloud and radiation test bed. Bull. Amer. Meteor. Soc., 75, 1201-1221.

Strassberg, D., M. LeMone, T. Warner, and J. Alfieri, 2008: Comparison of observed 10-m wind speeds to those based on Monin-Obukhov similarity theory using IHOP_2002 aircraft and surface data. Mon. Wea. Rev., 136, 964-972.

Trier, S. B., F. Chen, and K. W. Manning, 2004: A study of convection initiation in a mesoscale model using high-resolution land surface initial conditions. Mon. Wea. Rev., 132, 2954-2976.

Weckwerth, T., and Coauthors, 2004: An overview of the International $\mathrm{H}_{2} \mathrm{O}$ Project (IHOP_2002) and some preliminary highlights. Bull. Amer. Meteor. Soc., 85, 253-277.

Wyngaard, J. C., 2004: Toward numerical modeling in the "Terra Incognita." J. Atmos. Sci., 61, 1816-1826.

— L. J. Peltier, and S. Khanna, 1998: LES in the surface layer: Surface fluxes, scaling, and SGS modeling. J. Atmos. Sci., 55, 1733-1754.

Yates, D. N., F. Chen, M. LeMone, R. Qualls, S. Oncley, R. Grossman, and E. Brandes, 2001: A Cooperative Atmosphere-Surface Exchange Study (CASES) dataset for analyzing and parameterizing the effects of land surface heterogeneity on area-averaged surface heat fluxes. J. Appl. Meteor., 40, 921-937.

Zilitinkevich, S. S., 1995: Non-local turbulent transport: Pollution dispersion aspects of coherent structure of convective flows. Air Pollution III-Volume I. Air Pollution Theory and Simulation, H. Power, N. Moussiopoulos, and C.A. Brebbia, Eds., Computational Mechanics Publications, 53-60. 